\title{
Appropriateness of Neural Networks in Climate Prediction and Interpolations: A Comprehensive Literature Review
}

\author{
Sanjeev Karmakar \\ Bhilai Institute of Technology \\ Bhilai House, 491001, Durg \\ Chhattisgarh, India
}

\author{
Siddhartha Choubey \\ Shri Shankaracharya \\ Technical Campus / Shri \\ Shankaracharya group of \\ Institutions, Bhilai, Durg, India
}

\author{
Pradeep Mishra \\ Bhilai Institute of Technology, \\ Bhilai House, 491001, Durg \\ Chhattisgarh, India
}

\begin{abstract}
To be familiar with appropriateness of Neural Network in climate prediction and spatial interpolation, e comprehensive literature review of past 50 years is done and offered in this paper. And it is established that Neural Network such as BPN, $\mathrm{RBF}$ is best appropriate to be predicted chaotic behavior of climate variables like rainfall, rainfall runoff, and have efficient enough for prediction in long period. It is also found that Neural Network is significant for spatial interpolation of mean climate variables.
\end{abstract}

\section{Keywords}

Neural Network, Chaos, Prediction, Forecasting, Climate

\section{INTRODUCTION}

Climate prediction is one of the most imperative and demanding operational farm duties approved out through meteorological services world widely. It is also a complex process that includes multiple dedicated areas of skill. Researchers in this field have separated climate prediction procedures into two main branches in terms of numerical modeling and scientific processing of meteorological data. The most widespread techniques used for rainfall forecasting are the numerical and statistical methods. Still researches in these areas are being carried out for a long time; successes of these models are hardly ever observable. There is limited achievement in prediction the climate parameters using the empirically. The correctness of the models is needy upon the initial circumstances that are intrinsically unfinished. These systems are not clever to create acceptable consequences in local and short-term cases. The presentations, however, are unfortunate for long range prediction of climate still for the larger spatial scale and mainly, for the region of world where periodic monsoon happened. As an alternative, statistical methods in which climate time series are delighted as stochastic are extensively used for long-range predication of rainfall. India Meteorological Department (IMD) has been using statistical models for predicting monsoon rainfall.

Karmakar et al., 2008, 2009, has found that, the unpredictability of monsoon rainfall over the Indian region or very small scale geographical Indian region is due to external forcing i.e., global weather parameter and also the internal inconsistency within the time series itself. If outside forcing is assumed to be same then also there remains unpredictability within the time series that can only be explained if we are capable to predict the internal dynamical behavior of the weather data time series. The pattern recognition and prediction in a deterministic approach through
Neural Network technique based on back-propagation algorithm is established to be the well-organized way by which internal dynamics of chaotic time series data has been effectively recognized. Furthermore, pattern recognition and prediction have a longer lead-time as they can be made a year in advance. No other model apart from the neural network model so far has been intelligent to predict long-range climate.

Neural Network came into sciences in 1986 which is talented to obtain liberate of the discussed complexity and sketching substantial awareness of research workers, as be capable of handle the chaos prediction problems better than the conventional existing statistical methods.

The objective of this study is to expand and evaluate the neural network. This objective is considered via wide-ranging review of literature. It is found that, detail of discussion concerning the architecture of neural network for the same is rarely visible in the literature; however various applications of Neural Network are accessible. The paper has been created with the sections. Section 2 discussed a comprehensive review of world-wide contribution since 50 years. Results of the review has been discussed in section 3 and finally a conclusion is discussed in the section 4 .

\section{COMPREHANSIVE LITERATURE REVIEW}

\subsection{Rainfall Prediction}

After initial work of Walker [1, 2] several attempts by Gowariker et al., [3, 4], Thapliyal et al., [5, 6] have been made for developing better models for long-range forecasts of summer monsoon rainfall in India. Performance of the Gowariker et al., [4]; Rajeevan et al., [7, 8], Thapliyal et al., [9] regression models based on different sets of predictors have found to be satisfactory and reasonably accurate during last eleven years. These models are being extensively used by IMD for long-range forecasts of summer monsoon (June-September) rainfall over India as a whole. Recently, IMD has been trying to forecast for Indian sub regions and issuing long-range forecasts for three broad homogeneous regions of India, viz., Northwest India, Northeast India and the Peninsula through the updated three individual power regression models based on different sets of predictors [10]. However, Guhathakurta [11] found these statistical models to be successful in those years of normal monsoon rainfall and failed remarkably during the extreme monsoon years like 2002 and 2004. Also Rajeevan et al., Thapliyal et al., [5, 6, 8-10] have found that the statistical 
models have many inherent limitations. Guhathakurta et al., [12] have observed that the correlations between monsoon rainfall and the predictors can never be perfect and there is no ultimate end in finding the best predictors. Parthasarathy et al., Hastenrath et al., $[13,14]$ have found they may suffer epochal changes and there may be cross-correlations between the parameters. Rajeevan et al., Guhathakurta, Krishnamurthy et al., Sahai et al., [9, 15-18] have found that attempts to forecast monsoon rainfall as well as climate parameters through statistical technique over smaller areas like a district, or monsoon periods such as a July, monsoon (June-September), have become unsuccessful as correlations fall drastically. Guhathakurta $[19,20]$ has observed that the weather prediction over high-resolution geographical regions is very complicated. However, since 1986, the Neural Network technique has been drawing considerable attention of research workers, as it can handle the complex non-linearity problems better than the conventional existing statistical techniques.

In the case study of The chaotic time series of Indian monsoon rainfall, Basu and Andharia,1992,have found that the resulting forecast formula uses only the rainfall of past seven years as predictors, making a forecast eight months in advance[21].

After development of recurrent Sigma- Pi neural network rainfall forecasting system, Chow and Cho, 1997, have concluded that the neural network based now casting system is capable of providing a reliable rainfall now casting in Hong Kong [22].

Lee et al., 1998, have found that RBF networks produced good prediction while the linear models poor prediction [23]. Hsieh, W.H. and B. Tang, 1998, applied various Neural Network models for prediction and analysis in meteorology data as well as oceanography data and have found Neural Network technique is extremely useful [24]. In another research Dawson and Wilby have found that, rainfall runoff modeling, the ability of the Neural Network to cope with missing data and to "learn" from the event currently being forecast in real time makes it an appealing alternative to conventional lumped or semi distributed flood forecasting models [25]. Guhathakurta et al., have found that performance of the hybrid model (model III), has been the best among all three models developed. RMSE of this hybrid model is $4.93 \%$. As this hybrid model is showing good results it is now used by the IMD for experimental long range forecast of summer monsoon rainfall over India as a whole [26].

Ricardo et al.,1999, have used this technology for simulation of daily temperature for climate change over Portugal [27]. Wherein, performances of linear models and non-linear Neural Network are compared using a set of rigorous validation techniques. Finally, the non-linear Neural Network model is initialized with general circulation model output to construct scenarios of daily temperature at the present day (1970-79) and for a future decade (2090-99). Charles Jones and Pete Peterson, 1999, [28] have completed a research at the University of California, Santa Barbara, California, for air surface temperature prediction over the city. Guhathakurta, 1999, [29,30] has implemented this technique for short-term prediction of surface ozone at Pune city. In this work multiple regression data analysis using Neural Network technique has been used. It has been observed that, the parallel model can be developed for all the major cities with different sets of related data but the network architecture will be different.

After comparative study of short term rainfall prediction models for real time flood forecasting, E. Toth et al., have found that the time series analysis technique based on NEURAL NETWORK provides significant improvement in the flood forecasting accuracy in comparison to the use of simple rainfall prediction approaches [31]

In 2001 Luk et al., have developed and compared three types of Neural Networks suitable for rainfall prediction i.e. multilayer feed forward neural network, Elman partial recurrent neural network and time delay neural network [32]. Michaelides et al., have found that Neural Network is a suitable tool for the study of the medium and long term climatic variability. The Neural Network models trained were capable of detecting even minor characteristics and differentiating between various classes [33]. After a study of Radial Basis Function Neural Network (RBFNN), Chang et al., 2001, have found that RBFNN is a suitable technique for a rainfall runoff model for three hours ahead flood forecasting [34].

Brath et al., 2002, have presented time series analysis technique for improving the real time flood forecast by a deterministic lumped rainfall runoff model and they have concluded that apart from NEURAL NETWORKs with adaptive training, all the time series analysis techniques considered allow significant improvements if flood forecasting accuracy compared with the use of empirical rainfall predictors [35]. Using Neural Network for daily rainfall runoff modeling, Rajurkar et al., have found that coupling of Neural Network with a multiple-input singleoutput model predicted the daily runoff values with high accuracy both in the training and validation periods [36]. For a rainfall runoff relationship Harun and Irwan, 2002, have concluded that the performance of neural network model is better than HEC-HMS and MLR models for modeling the rainfall runoff relationship [37]. Iseri et al., 2002, have developed medium term forecasting of August rainfall in Fukuoka city. In order to identify the sufficient predictors, the partial mutual information was used for the candidate predictors, which are Sea Surface Temperature anomalies (SSTa) in the Pacific Ocean and three climate indices. When data with lead times between one and twelve months were used to forecast August rainfall, it was found that a model with the North Pacific index and selected SSTa as inputs performed reasonably well [38].

Silva and Snell et al., 2003, have applied this approach both in terms of predictive accuracy and model encompassing. This technology is currently being widely applied to climate prediction because of its ability to explain the complex behavior through time series as well as regression data analysis $[39,40]$. Richard 2003, has completed simulation of European climate, through this technique. In that study, Neural Network was used for linear regression analysis [41].

In 2004 Maqsood et al., have found that HFM is relatively less accurate and RBFN is relatively more reliable for the weather forecasting problems and in comparison the ensembles of neural networks produced the most accurate forecast [42]. After applying soft computing techniques Pasero and Moniaci, 2004, have found that the system is able to forecast the evolution of the parameters in next three hours giving previous indications about the possibility of rain, ice and fog [43]. Lekkas et al., 2004 have used a multilayer back propagation network and found that BPNN will not always find the correct weight and biases fort the optimum solution, whereas their results supported the hypothesis that Neural Network can produce qualitative forecast. A 7 hour ahead forecast in particular proves to be of fairly high precision, especially when an error prediction technique is introduced to the Neural Network model [44]. Chang Shu and Donald H. 
Burn, 2004, have found that artificial neural network ensembles generate improved flood estimates and are less sensitive to the choice of initial parameters when compared with a single artificial neural network [45]. In 2004 Nayak et al., have presented the application of an adaptive neuro-fuzzy inference system (ANFIS) to hydrologic time series modeling, and it was observed that the ANFIS model preserves the potential of the Neural Network approach fully, and eases the model building process [46]. M.Asce et al., 2004, have applied two Neural Network -hydrologic forecasting models and they found encouraging results indicating that Neural Network -hydrologic forecasting models can be considered an alternate and practical tool for stream-flow forecast [47]. In 2004 R.E. Abdel-Aal, studied alternative abductive networks approach, and concluded that the performance is significantly superior to naive forecasts based on persistence and climatology [48]. In coastal areas it is an enormous prediction of tidal level, Tsong-Lin Lee, 2004, has predicted long-term tidal level using back propagation neural network, as compare to conventional harmonic method, he concluded that back-propagation neural network mode also efficiently predicts the long-term tidal levels [49].

To estimate the maximum surface temperature and relative humidity a Feed forward multi-layered artificial neural network model is designed by Chaudhuri, and Chattopadhyay, in 2005, and stated that one hidden-layer neural network is an efficient forecasting tool by which an estimation of maximum surface temperature and maximum relative humidity can be obtained [50]. A further contribution of Gwo-Fong Lin* and Lu-Hsien Chen, 2005, in neural network is that, two hidden layers is developed to forecast typhoon rainfall, and it has been observed that the forecasting model can produce reasonable forecasts [51]. Using an innovation in the researches Jon Vandegriff et al., 2005, have studied Forecasting space weather with Neural Network and they found that an artificial neural network can be trained to predict the shock arrival with better accuracy than existing methods [52]. Ozgur KISI, 2005, has selected three simple neural network (NN) architectures, i.e. Artificial Neural Networks, Auto-Regressive Models and sum of square errors, for comparison of forecasting probabilities and he found that NNs were able to produce better results than AR models when given the same data inputs [53]. Exploring the new concept, soft computing models based on Radial Basis Function Network for 24-h weather forecasting, Maqsood et al., have concluded that the RBFN produces the most accurate forecasts compared to the MLP, ERNN and HFM [54].

In 2006, Somvanshi et al., have proved that Neural Network model can be used as an appropriate forecasting tool to predict the rainfall, which out performs the ARIMA (Autoregressive Integrated Moving Average) model [55]. As in the previous researches we have observed that most of the researchers have been used Artificial Neural Network for various Neural Networkual predictions like rainfall, tide, temperature etc, but in this study Niravesh Srikalra and Chularat Tanprasert have used Artificial Neural Network for daily rainfall prediction in Chao Phraya River with Online Data Collection, and they found that it is possible to predict rainfall on daily basis with acceptably accuracy using Artificial Neural Network [56]. A.D. Kumarasiri and D.U.J. Sonnadara, 2006, have applied an innovative technique for rainfall forecasting using Artificial Neural Networks based on feed-forward back-propagation architecture. Three Neural Network models were developed; a one-day-ahead model for predicting the rainfall occurrence of the next day, which was able to make predictions with a $74.25 \%$ accuracy, and two long term forecasting models for monthly and yearly rainfall depth predictions with $58.33 \%$ and $76.67 \%$ accuracies within a 5\% uncertainty level [57]. D. Nagesh et al., 2006, have used Artificial Intelligence techniques for forecasting regional rainfall and they found that this technique shows reasonably good accuracy for monthly and seasonal rainfall forecasting [58]. Guhathakurta, 2006, developed a model for rainfall forecast for the Kerala sub-division based on the area weighted value of all district forecast. The performance was found satisfactory than the statistical technique [59].

As per the utmost necessities of the hydrologists around the globe, Bustami et al., 2007, have studied Neural Network for precipitation and water level prediction; they found that Neural Network is an effective tool in forecasting both missing precipitation and water level data [60]. Paras et al., 2007, have introduced a pioneering Feature Based Neural Network Model for Weather Forecasting and the results were very encouraging and it is found that the feature based forecasting model can make predictions with high degree of accuracy [61]. Mohsen Hayati, and Zahra Mohebi, 2007, have used Neural Network in a new experiment of short term temperature forecasting(STTF) and he found that MLP network has the minimum forecasting error and can be considered as a good method to model the STTF systems [62]. Using time series of draught indices with artificial neural network Morid et al., 2007, have tested number of different Neural Network models for both Effective Drought Index (EDI) and the Standard Precipitation Index (SPI) with the lead times of 1 to 12 months [63]. As load forecasting is an important prediction aspect for industrial sectors all over the world, Mohsen Hayati, and Yazdan Shirvany, 2007, have put in an approach for short term load forecasting (STLF) using Artificial Neural Network, and they concluded that MLP network has the minimum forecasting error and can be considered as a good method to model the STLF systems [64]. To apply a reliable and robust procedures for monthly reconstruction of precipitation time series, Lucio et al., 2007, have found that Artificial Neural Network can be applied to explore the spatiotemporal dependence of meteorological attributes [65]. In another experiment HartmNeural Network et al., 2007, have found that the neural network algorithms are capable of explaining most of the rainfall variability even it can predict the summer rainfall also [66].

Aliev et al., 2008, have proposed, fuzzy recurrent neural network (FRNN) based time series forecasting method for solving forecasting problems, in an experiment and they found that The performance of the proposed method for forecasting fuzzy time series shows its high efficiency and effectiveness for a wide domain of application areas ranging from weather forecasting to plNeural Networking in economics and business [67]. Chattopadhyay and Chattopadhyay, 2008, have worked out to find out best hidden layer size for three layered neural net in predicting monsoon rainfall in India, and they have found that eleven-hidden-nodes three-layered neural network has more efficacy than asymptotic regression in the present forecasting task [68]. Hung et al., 2008, have developed a new Neural Network model for forecasting rainfall from 1 to $6 \mathrm{~h}$ ahead at 75 rain gauge stations in the study area as forecast point from the data of 3 consecutive years (1997-1999), and they observed that the developed Neural Network model can be used for real-time rainfall forecasting and flood management [69]. In an comparative study between Artificial Intelligence and Artificial Neural Network for rainfall runoff modeling, Aytek et al.,2008, have found that genetic programming (GP) formulation performs quite well compared to results obtained by Neural Network s and is quite practical for use. It is concluded from the 
results that GEP can be proposed as an alternative to Neural Network models [70]. Chattopadhyay et al.,2008, have studied the complexities in the relationship between rainfall and sea surface temperature (SST) anomalies during the winter monsoon using scatter plot matrices and autocorrelation functions, and they found that the statistical assessment revealed the potential of artificial neural network over exponential regression [71]. However Mar, and Naing, 2008, have tested more over 100 cases by changing the number of input and hidden nodes from 1 to 10 nodes, respectively, and only one output node in an optimum artificial neural network architecture and they concluded that 3 inputs- 10 hiddens- 1 output architecture model gives the best prediction result for monthly precipitation prediction [72].

Karmakar et.al., 2008, have developed a Satellite Based Agriculture Meteorological Information System (AGRIMETCast) in the Context of Remote Places of Chhattisgarh Using Remote Sensing Data [73]. Again Karmakar et al., 2008, have developed the Neural Network models for Long-Range Meteorological Parameters Pattern Recognition over the Smaller Scale Geographical Region and the performances of these models in pattern recognition and prediction have been found to be extremely good [74].

Hocaoglu et al., 2009, have developed adaptive neuro-fuzzy inference system for missing wind data forecasting [75]. In a Case Study on Jarahi Watershed, Karim Solaimani, 2009, has studied Rainfall-runoff Prediction Based on Artificial Neural Network and he found that Artificial Neural Network method is more appropriate and efficient to predict the river runoff than classical regression model [76]. KOŠCAK et al., 2009, have compared common meteorological forecasting method with Neural Network and he found the performance of Neural Network with high accuracy [77]. Karamouz et al., 2009, have experimented to perform long lead rainfall forecasting Using Statistical Downscaling and Artificial Neural Network Modeling; finally they found that the SDSM outperforms the NEURAL NETWORK model [78]. In a comparative study between ASTAR and ARIMA methods for rainfall forecasting in Indonesia Otok, and Suhartono, 2009, have concluded that the best model is ASTAR model both in sample and out-sample data [79].

It can be well-known that neural network can applied for most of the prediction aspects, Nekoukar et al., 2010, have used radial basis function neural network for financial time-series forecasting, and the result of their experiment shows the feasibility and effectiveness [80]. Weerasinghe et al., 2010, have tested the performance of neural network, in an experiment, for forecasting daily precipitation using multiple sources, A cluster of ten neighboring weather stations having 30 years of daily precipitation data $(1970$ - 1999) was used in training and testing the models. Twenty years of daily precipitation data were used to train the networks while ten years of daily precipitation data were used to test the effectiveness of the models. They found that the models were able to predict the occurrence of daily precipitation with an accuracy of $79 \pm 3 \%$ and Fuzzy classification produced a higher accuracy in predicting 'trace' precipitation than other categories [81]. Luenam et al, 2010 have presented a Neuro-Fuzzy approach for daily rainfall prediction, and their experimental results show that overall classification accuracy of the neuro-fuzzy classifier is satisfactory [82]. Wu et al., 2010 have attempted to seek a relatively optimal data-driven model for Rainfall time series forecasting using Modular Artificial Neural Networks, they found that the normal mode indicate, M- Neural Network performs the best among all four models, but the advantage of M-Neural Network over Neural Network is not significant in monthly rainfall series forecasting [83]. To predict the intensity of rainfall using artificial neural network Nastos et al., 2010 have developed prognostic models and they have proved that the results of the developed and applied Neural Network models showed a fairly reliable forecast of the rain intensity for the next four months [84]. Patil and Ghatol, 2010, have used various Neural Network topologies such as radial basis functions and multilayer perceptron with Levenberg Marquardt and momentum learning rules for predicting rainfall using local parameters and they found the topologies fit for the same task [85]. Tiron, and Gosav, 2010, have estimated rainfall from BARNOVA WSR-98 D Radar using Artificial Neural Network and the efficiency of Neural Network network in the estimation of the rain rate on the ground in comparison with that supplied by the weather radar is evaluated [86]. Goyal and Ojha, 2010, have focused their working on a concept of using dimensionless variables as input and output to Artificial Neural Network, finally they have concluded that Neural Network model using dimensionless variables were able to provide a better representation of rainfallrunoff process in com-parison with the Neural Network models using process variables investigated in this study [87]. On the basis of humidity, dew point and pressure in India, Enireddy et al., 2010, have used the back propagation neural network model for predicting the rainfall. In the training they have obtained $99.79 \%$ of accuracy and $94.28 \%$ in testing. From these results they have concluded that rainfall can predicted in future using the same method [88]. Haghizadeh et al., 2010, have proposed Neural Network model and Multiple Regression (MR) for prediction of total sediment at basin scale and they found that estimated rate of sediment yield by Artificial neural networks is much better fits with the observed data in comparison to MR model [89]. Subhajini and Raj, 2010, have put in a Computational Analysis of Optical Neural Network Models to Weather Forecasting; in this study they have compared Electronic Neural Network (ENN) model and opto-electronic neural network model. Overall their conclusion was, the training of opto-electronic neural network is fast compared to Neural Network. The accuracy of optoelectronic neural network is as good as ENN [90]. Durdu Omer Faruk, 2010, has experimented with A hybrid neural network and ARIMA model for water quality time series prediction. He has provided the results that the hybrid model provides much better accuracy over the ARIMA and neural network models for water quality predictions [91]. To identify and forecast the intensity of wind power and wind speed, Soman et al., 2010, have applied artificial neural network and hybrid techniques over different time-scales, they found the accuracy in prediction associated with wind power and speed, based on numeric weather prediction (NWP) [92].

Forecasting daily rainfall at Mashhad Synoptic Station, Khalili et al., 2011, have applied Artificial Neural Networks model and they found that the black box model is capable of predicting the rainfall [93]. Pan et al., 2011, have experimented with feed forward neural network to predict Typhoon Rainfall. FNN is applied to estimate the residuals from the linear model to the differences between simulated rainfalls by a typhoon rainfall climatology model (TRCM) and observations and their results were satisfactory [94]. Joshi and Patel, 2011, have put in a review report on Rainfall-Runoff modeling using Neural Network, in the same study they have reviewed three neural network methods, Feed Forward Back Propagation (FFBP), Radial Basis Function (RBF) and Generalized Regression Neural Network (GRNN) and they have seen that GRNN flow 
estimation performances were close to those of the FFBP, RBF and MLR [95]. El-Shafie et al., 2011, have developed two rainfall prediction models i.e. Artificial Neural Network model and Multi regression model (MLR). An analysis of two statistical models developed for rainfall forecast on yearly and monthly basis in Alexandria, Egypt shows that an Neural Network has a better performance than an MLR model [96]. Rainfall forecasting in a mountainous region is a big task in itself Mekanik et al., 2011, have tried to do it using Neural Network modeling a feed forward Artificial Neural Network (Neural Network) rainfall model was developed to investigate its potentials in forecasting rainfall. A monthly feed forward multi layer perceptron neural network rainfall forecasting model was developed for a station in the west mountainous region of Iran [97]. The temperature has a great effect in forecasting rainfall Amanpreet Kaur, and Harpreet Singh, 2011, have tested Artificial Neural Network in forecasting minimum temperature, they have used multi layer perceptron architecture to model the forecasting system and back propagation algorithm is used to train the network. They found that minimum temperature can be predicted with reasonable accuracy using Neural Network model [98]. El-Shafie et al., 2011, have proposed an idea of using adaptive neuro-fuzzy inference system based model for rainfall forecasting on monthly basis and they found that the ANFIS model showed higher rainfall forecasting accuracy and low error compared to the Neural Network model [99]. Tripathy et al., 2011, have experimented with Artificial Neural Network and Particle Swarm Optimization (PSO) Technique for weather forecasting and their experimental results indicate that the proposed approach is useful for weather forecasting [100]. As we have observed that many of the scientists have used Neural Network and various Neural Network models for forecasting Rainfall, Temperature, Wind and Flood etc., El-Shafie et al., 2011, have compared and studied Dynamic Vs Static neural network models for rainfall forecasting, they have developed AI based forecasting architectures using Multi-Layer Perceptron Neural Networks (MLPNN), Radial Basis Function Neural Networks (RBFNN) and Adaptive Neuron-Fuzzy Inference Systems (ANFIS), finally they concluded that the dynamic neural network namely IDNN could be suitable for modeling the temporal dimension of the rainfall pattern, thus, provides better forecasting accuracy [101]. Geetha and Selvaraj, 2011, have predicted Rainfall in Chennai using back propagation neural network model, by their research the mean monthly rainfall is predicted using Neural Network model. The model can perform well both in training and independent periods [102]. In various researches Artificial Neural Networks (have been extensively used for simulation of rainfall-runoff and other hydrological processes. Reshma et al., 2011, have applied Artificial Neural Network for determination of Distributed Rainfall- Runoff Model Parameters and they found that the Neural Network technique can be successfully employed for the purpose of estimation of model parameters of distributed rainfall-runoff model [103]. Mohan Raju et al., 2011, have developed Artificial Neural-Network-Based Models for the Simulation of Spring Discharge, as their training and testing results revealed that the models were predicting the weekly spring discharge satisfactorily [104]. Predicting groundwater level is somehow a difficult task now a day because it varies place to place and round the globe, Mayilvaganan, and Naidu, 2011, have attempted to forecast groundwater level of a watershed using Neural Network and Fuzzy Logic. A three-layer feed-forward NEURAL NETWORK was developed using the sigmoid function and the back propagation algorithm. Now it has been observed that Neural Network s perform significantly better than
Fuzzy Logic [105]. El-shafie et al., 2011, have tried to use neural network and regression technique for rainfall-runoff prediction finally they concluded that the results showed that the feed forward back propagation Neural Network can describe the behaviour of rainfall-runoff relation more accurately than the classical regression model [106]. In another research integrated artificial neural network-fuzzy logic-wavelet model is employed to predict Long term rainfall by Afshin et al., 2011. The results of the integrated model showed superior results when compared to the two year forecasts to predict the six-month and Neural Networkual periods. As a result of the root mean squared error, predicting the two-year and Neural Networkual periods is 6.22 and 7.11, respectively. However, the predicted six months shows 13.15. [107]. Siou et al., 2011, have experimented with Complexity selection of a neural network model for flood forecasting, these models yield very good results, and the forecasted discharge values at the Lez spring are acceptable up to a 1-day forecasting horizon [108]. Saima et al., 2011, have reviewed on the various forecasting methods and hybrid models, they have put in a contradictory conclusion that there is no such model exists that can forecast accurately in all situations. This is because the distinct nature of the model [109].

At the end of literature survey from 1923 - 2012, In 2012, Sawaitul et al., have presented an approach for classification and prediction of future weather using back propagation algorithm, and discussed different models which were used in the past for weather forecasting, finally the study concludes that the new technology of wireless medium can be used for weather forecasting process. It also concludes that the Back Propagation Algorithm can also be applied on the weather forecasting data. Neural Networks are capable of modeling a weather forecast system [110].

\subsection{Rainfall-Runoff Modeling}

The significant contributions in the field of R-R modelling from 1979 to 2013 are reviewed and identified very vital methodologies. The major contributions are discussed in this section. Initial work of in this research area, Kitanindis \& Bras. (1979), have applied ridge regression technique and this technique Provides parameter estimates that seem more intuitive and it handles co- linearity problems in a consistent objective mNeural Networker and without endangering regression accuracy [115]. After that Kitanindis \& Bras., (1980), have developed 'kalman filter' which is used in real time river discharge forecasting [116].

Martinec (1982) has found Deterministic approach require measurements of the snow covered area provided by remote sensing for short-term discharge forecasts [117]. Baumgartner et al., (1987) Derived the main input variable for a deterministic snowmelt runoff model (SRM), it is "guaranteed snow cover information" for a specific area and time [118]. Vandewiele.\& Yu. (1992), have used statistical methodology for calibrating the models of given catchments is described, it reduces essentially to regression analysis, including residual analysis, sensitivity to calibration period and extrapolation test. The results of applying the new models are satisfactory from a statistical point of view [119].

In the major work in 1993, Shashikumar et al., have developed Snowmelt Runoff Model (SRM) using variables like temperature, precipitation and snow covered area along with some externally derived parameters like temperature lapse rate, degree-day factore and this Snowmelt Runoff Model is useful for snowfed river basins, especially where meteorological and hydrological data are limited [120]. Kember, et al., has used 
Nearest Neighbor Method (NNM), The NNM model is found to improved Forecasts as compared to Auto -Regressive Intgreted Moving Average (ARIMA) models [121].

Seidel, et al., (1994) has observed Runoff is computed by the SRM model with snow covered areas as well as temperature and precipitation forecasts as input variable. These runoff forecasts can be exploited, among other purposes, for optimizing the hydropower production and for tamely Decisions on the electricity market[122].Shi, et al., (1995) have used polarimetric model and polarimetric model shows that scattering mechanisms control the relationship between snow wetness and the copolarization signals in data from a multi-parameter synthetic aperture radar [123]. Franchinia, et al., (1996) have observed that the stochastic storm transposition( SST) approach have been converted to a range of possible flood peak values using a rainfall-runoff model (the ARNO model) and a probabilistic disaggregation scheme of cumulative storm depths to hourly data. The SST approach has been extended to a probabilistic procedure for estimation of Neural Networkual exceedance probabilities of flood peaks by coupling it with a rainfall-runoff model [124].

After the development of linear model as discussed above, a non-linear perturbation model (NLPM) for river flow forecasting is developed by Xia et al., (1997) based on consideration of catchment wetness using an antecedent precipitation index (API). It is found that the NLPM-API model was significantly more efficient than the original linear perturbation model [125]. Franchini,et al,1997, have Compared several genetic algorithm(GA)schemes, GA is connected with a conceptual rainfall-runoff model, is such as to make the GA algorithm relatively inefficient[126]. Bach, et al., (1999) have developed forecast system uses hydrological model used for the translation of rainfall into runoff and this model has been modified to allow remote sensing inputs in an automated way using Geographical Information System (GIS) tools. This technique improve flood forecast through a better estimation of spatial input parameters [127].

The important contributions in 1999, A case study for Singapore rainfall data was done by Sivakumar, et al., The results indicated a noise level between 9 and $11 \%$ proposed a systematic approach to additive measurement noise reduction in chaotic hydrological (or any real) data, by coupling a noise level determination method and a noise reduction method. This approach uses the prediction accuracy as the main diagnostic tool to determine the most probable noise level, and the correlation dimension as a supplementary tool [128]. Sajikumar, et al., have implemented a simple"black box" model to identify a direct mapping between the inputs and outputs without detailed consideration of the internal structure of the physical process and Compared with a conceptual rainfall-runoff model ,it was slightly better for a particular river flow-forecasting problem [129]. During the growth of NEURAL NETWORK concept, Dibike and Solomatine have analysed two types of NEURAL NETWORK architectures, namely multi-layer perceptron network (MLP) and radial basis function network (RBN) and have concluded that NEURAL NETWORK based forecast model is better than conceptual model[130].

In 2000, Gomez-Landesa and Rangol, have presented sub-pixel approach to obtain the percent of snow covered area in each Advanced Very Hight Resolution Radiometer (AVHRR) pixel, using chNeural Networkels 1 and 2 [131]. Schaper \& Seidel., have used GIS based extrapolation techniques to evaluate cloud and forest covered areas with respect to snow cover and showed a method to calculate runoff from snow- and icemelt using meteorological data and remote sensing derived snow and ice cover maps and address the problem of snow mapping of small basins with areas only 10 times the spatial resolution of the sensor using subpixel analysis [132]. Toth et al., have used linear stochastic auto-regressive moving average (ARMA) models, Neural Network and the non-parametric nearestneighbours method as well as analyse and compare the relative advantages and limitations of each time-series analysis technique, used for issuing rainfall forecasts for lead-times varying from 1 to $6 \mathrm{~h}$. The results also indicate a significant improvement in the flood forecasting accuracy [133]. Mallor, et al., have develop a catchment runoff forecasting system which provides an ensemble of hydrograph Scenarios rather than a single uncertain estimation [134].

In the considerable contributions in 2001, Sivapragasam, et al., Singular Spectrum Analysis (SSA) coupled with Support Vector Machine (SVM) techniques have been used and SSA-SVM technique found $58.75 \%$ improvement over non-linear prediction (NLP) in the runoff prediction for catchment [135] Chang, et al., applied and modify radial basis function (RBF) neural network (NN) and the modified RBF NN is capable of providing arbitrarily good prediction of flood flow up to three hours ahead [136].

In 2002, G'omez-Landesa and Rango., have developed snowmelt runoff model (SRM )using NOAA-AVHRR satellite data as well as Comparisons of forecasted and measured values for the first three basins with available 1998 data show quite good results (volume difference of 98\%) for the largest basin (572.9 km2) [137]. Randall and Tagliarini., have used feed forward neural networks (FFNNs) technique and this technique provides better forecasting results rather than ARMA (AutoRegressive Moving Average) techniques [138]. CNeural Networkas, et al., have Used neural network based approach with feedforward, MultiLayer Perceptrons (MLPs) and this neural models applied to the rainfall runoff transformation problem could provide a useful tool for flood prediction water system [139]. Karna,et al., have combined assimilation technique with SAR observations to runoff model by applying a constrained iteration procedure and forward modelling of SAR observations then improves the performance of the discharge forecasting model [140]. Breath et al., presented time series analysis technique for improving the real time flood forecast by deterministic lumped rainfall runoff model and they have concluded that apart from Neural Networks with adaptive training, all the time series analysis techniques all the time series analysis techniques considered allow significant improvements if flood forecasting accuracy compared with the use of empirical rainfall predictors [141].

In the significant contributions in 2003, Mahabir,et al., have applied fuzzy logic modelling techniques and this technique provides more accurate quantitative forecast [142]. Slomatine and Dulal, have used Neural Networks and model trees (MTs) technique and concluded that Both techniques have almost similar performance for 1-h ahead prediction of runoff, but the result of the Neural Network is slightly better than the MT for higher lead times [143]. Gaume and Gosset., have employed Feed Forward Artificial Neural Network (FFNN) and The FFNN model appear to be better forecasting tools than linear models The FFNN model can be efficient only if those function are suitable for the process to be simulated [144].

The major work in 2004, Hossain et al., have studied satellite rainfall error model (SREM) to simulate passive microwave 
(PM) and infrared (IR) satellite rainfall and it is useful for the design, plNeural Networking, and application assessment of satellite remote sensing in flood and flash flood forecasting [145]. Tigkas and Tsakiris, have Used software package Med basin based on the Deterministic lumped,conceptual model of FAO and MERO and the model performance is considered satisfactory based on a number of application in hydrological basins in the Mediterranean region [146]. Murphy et al., have used HYSIM, is a hydrological simulation model with GIS and found satisfactory results being obtained across a wide variety of basins in terms of floods and droughts as well as the magnitude and frequency [147].

In the significant contributions in 2005, Corani and Guariso have applied neural networks and fuzzy logic Technique and Performance improvements have been found by comparing the proposed framework approach with respect to traditional Neural Network for flood forecasting [148]. Khan \& Coulibaly, have introduced a Bayesian learning approach for Neural Network modelling $(\mathrm{BNN})$ of daily streamflows implemented with a multi-layer perceptron (MLP) and have concluded that BNN model is better than the non-Bayesian model for forecasting [149]. Valença, et al., have applied constructive neural networks model. This model was provided better representation of the daily average water inflow forecasting, than the models based on Box-Jenkins method, it was used on the Brazilian Electrical Sector [150] Knebl et al., have developed a framework for regional scale flood modelling that integrates GIS, and a hydrological model (HEC- HMS/RAS). They proposed a methodology and developed a flood model that may be incorporated into both regional hydrological studies and/or a regional alert system for hazard mitigation [151]. Nayak, et al., have used fuzzy computing approach and have provided quick prediction based solely on forecast values and improved the forecasts at greater lead times [152].

In 2006, Chang and Guo, proposed motes-based sensor network has three major modules, which are water level monitoring module, network video record module, and data processing module and This technique provides system architecture for final verification of flooding situation [153]. Ghedira, et al, have used Neural Network system and concluded that the performance of neural network reaches $82 \%, 10 \%$ higher than the filtering algorithm for the test data sets (not used in the neural network training process) [154]. Liu,et al., have studied time series Transfer Function Noise (TFN) of time series, the Grey system(GM), and the adaptive network based fuzzy inference system (ANFIS) and found that adaptive network based fuzzy inference system (ANFIS) is better [155]. Li, et al., have applied Fuzzy neural network and this model increased the network ability to model complicate nonlinear problems such as runoff forecast. Khan and See, have studied one statistical and three Data-driven modelling (DDM) approaches and found that DDM is better than Statistical approach [156]. Huan, et al., have applied hydrological model and Cellular Automata (Hydro CA routing model) and found result that the precision of topographic index (TOPMODEL) simulation can be improved by using HydroCA routing model from $64.7 \%$ to $71.0 \%$ and SCS simulation from $54.7 \%$ to $57.5 \%$ [157]. Du, et al., have proposed Grid based digital elevation model (DEM) with GIS and This model can simulate reasonably well for the runoff hydrograph at the catchment outlet [158]. Tayfur, et al., have applied Neural Network fuzzy logic (FL) and kinematic wave approximation (KWA) models and found Neural Network and FL models are used to predict runoff at a very small scale of a flume $6.9 \mathrm{~m} 2$, a larger scale of a plot $92.4 \mathrm{~m} 2$, and a small scale of a watershed $8.44 \mathrm{~m} 2$. it is easier to construct NEURAL NETWORK and FL models than KWA model[159].

In the important contributions in 2007, Cheng, et al., have proposed Bayesian forecasting system (BFS) framework, with back propagation neural network (BPN) and this technique not only increases forecasting precision greatly but also offers more information for flood control [160]. Jiang, et al., have introduced Fletcher-Reeves algorithm in BPN model and found that this model can enhance the convergence rate without increasing its complexity, so as to improve the forecasting precision of the BPN model [160]. Ju, et al., have used BPN model and studied comparison of with Xinanjiang model indicates that BPN performs well on the streamflow simulation and forecasting [161]. After using BPN, Broersen, has introduced auto regressive moving average (ARMA) time-series models and its performed well for small samples [162 Ji \& Bende, have applied SCEM-UA algorithm and the SCEM-UA algorithm is used for nonlinear monthly runoff series prediction [163]. Moore, has developed Probability distributed model(PDM) and PDM is used for real time forecasting[164]. Lohani, et al., have used fuzzy logic technique and the fuzzy modelling approach is slightly better than the Neural Network [165]. Jenicek, studied hydrologic engineering centre-hydrologic modelling system (HEC-HMS),MIKE-SHE, sacramento-soil moisture account (SAC-SMA), niederschlag-abfluss simulation model (NASIM) ,HBV and many others and found that These method are possible to use by solution of various types of hydrological tasks such as operational hydrology floods, drought protection or pollution transport modelling [166]. Jingbo, et al., have applied the statistic method of BDS and this technique is used in runoff forecasting [167].

In the noteworthy contributions in 2008, Lake and Funkquist, have applied three-dimensional baroclinic ocean model high resolution operational model (HIROMB) and one-dimensional biogeochemical model, swedish coastal and ocean biogeochemical model (SCOBI). This technique producing high quality daily algae forecasts which can be used in environmental surveillance and monitoring purposes [168]. Li and Yuan, have used data mining technology with Neural Network as well as this approach needs less input data requirement, less maintenance and performs more simple forecasting process and Good precision of forecasting [169]. Liu, et al, have designed Adaptive-Network Based Fuzzy Inference System (ANFIS) and concluded that ANFIS was better than ARMA Model [170]. Pei $\&$ Zhu, have used fuzzy inference technique and found that the results indicate that the model can effectively select the forecast factors and the forecast precision is improved [171]. Xu, et al., BPN model, distributed hydrological model had been used and the simulated results of the BPN model indicate a satisfactory performance in the daily-scale simulation than distributed hydrologic model [172]. Sang \& Wang, have applied stochastic model for mid-to-long term runoff forecast is built by combining Wavelet Analyze (WA), Neural Network and hydrologic frequency analysis and Compared with traditional methods, this model is of higher accuracy, high eligible rate, and improve the performance of forecast results about the runoff series [173]. Liu \& Jiang, have proposed nonlinear forecast modelling based on wavelet analysis. It is effective method and is able to provide good accuracy and efficiency and satisfying forecast results under different time scales [174]. Sun, et al, BP neural network model with space reconstruction theory and the result shows that the model has a very good forecast accuracy and value [175] .Liu, et al., have Improved Markov Chain Monte Carlo (MCMC) algorithm and found Improved (MCMC) algorithm 
which is useful for parameter estimation of complex modelling and uncertainty analysis [176]. Wiriyarattanakul, et al., have applied fuzzy support vector machine regression (FSVMR) and the FSVMR method is more effective and efficient in forecasting Runoff than the standard support vector machines regression (SVMR) [177]. Guo, et al., have proposed wavelet analysis and artificial neural network model and the result shows that this model can get a good result in simulating and predicting monthly runoff [178]. Remesan, et al., have used Neural Network Auto Regressive with exogenous input (NNARX) and adaptive neuro-fuzzy inference system (NIFS). ANFIS and NNARX models can be applied successfully in rainfall-runoff modelling to achieve highly accurate and reliable forecasting results [179]. Archer and Fowler, have used A multiple linear regression model and have concluded that the simple regression model based on observed surface precipitation and temperature is used for forecasting seasonal runoff [180]. Aytek,et al., have analyzed genetic programming (GP) technique, Neural Network techniques:(i)the BPN and (ii) generalized regression neural network (GRNN) methods and found that (GP) formulation performs quite well compared to results obtained by Neural Networks. Gene expression programming(GEP) can be proposed as an alternative to Neural Network models [181]. Solaimani, has used Artificial Neural Network with feed forward back propagation and found the Neural Network method is more appropriate and efficient to predict the river runoff than classical regression model [182].

In the significant contributions in 2009, Zhang, et al., have established error correction model based on the theory of cointegration is established on the foundation of the stable data and concluded that the method has good development and application prospects in hydrological forecasting [183]. Ren and Hao, have Described mid-long term runoff prediction using moving windows autoregressive quadratic model (MWAQM).and Compared with Neural Network, the MWAQM has advantages that are simpler structure, less parameters and more convenient calculation [184]. Wang, et al., have used SQL Server, GIS. It provides important early warning and decision making Support on flood prevention with more friendly interface [185]. Ping has combined technique of Neural Network. Wavelet transformation and solving the non-stationary time series problem. This method is feasible and effective [186]. In the case study, Zhu and Pei have applied Wavelet Algorithm found that Forecast precision is improved [187]. Min and Wu have proposed local semi-linear regression (LSLR) technique and Experimental results show that this technique can achieve an accuracy of $86.68 \%$ while the error tolerance is only $\pm 1.5 \%$ in flood seasons [188]. Lu \& Chen, have combined the GIS technology with the hydrodynamic method and This method proves that it is very applicable and the calculation speed is quick and the calculation accuracy is high .At present, the method has been applied in the Three Gorges Reservoir's realtime operation [189]. Yan, et al., have used BP neural network model. BP model has high accuracy and can be used to forecast runoff and the sediment transport volume during the flood period and non-flood period [190]. In the duration of development of rainfall-runoff modelling Yan, et al., have proposed RBF and ccompared the RBF emulating results with the field data, the forecasting error is analyzed and the methods to improve the forecast precision [191] . Luna, et al., have applied fuzzy inference system (FIS) approach and have concluded that FIS approach is better than Soil Moisture Accounting Procedure (SMAP) approach it is promising for daily runoff forecasting [192]. Sihui, has developed single element medium and long-term classification forecast model and the result indicates that the forecast model can describe the relationship between forecast factors and forecast object efficiently and accurately, the model is more credible, if the quantity of swatches is larger [193]. Guo, et al., have designed rough set theory (RST) approach, RST not only reduced the dimension and noise of the predictor variables dataset greatly in each grid, but also enhanced the performance of statistical downscaling models [194]. Acar, et al., have combined Snowmelt runoff model with GIS and it is used to forecast the river discharges [195]. Xu, et al., have used BPN and Compared between BPN models and four process-based models, namely a lumped model(Xinanjiang), a semi-distributed model (XXT), and ESSI and SWAT (two distributed models). It is found that all the four process-based models perform poorer compared with BPN models for I-day lead time to 20-day lead time [196]. Xui, et al., have applied TOPMODEL, Digital Elevation Model (DEM) and TOPMODEL can be used as a stream flow prediction tool and hence as an agricultural drought forecasting tool [197]. Feng and Zhang, have used back propagation Neural Network and found that the Neural Network technology is a relatively effective way of solving problems in forecast of surface runoff [198]. Hundecha, et al., have developed fuzzy logic-based rainfall-runoff model and have concluded that Fuzzy logic-based rainfall-runoff model is better than HBV model. This approach is easier and faster to work with [199]. Bulygina, et al., have used base flow index (BFI) from HOST database and . HOST is a simple and potentially powerful method of conditioning the parameter space under current and future land management [200]. Hung, et al., have utilized NEURAL NETWORK technique and found that the superiority in performance of the NEURAL NETWORK model over that of the persistent model. NEURAL NETWORK improves the forecast accuracy and efficiency [201].

In 2010, Dadhwala, et al., have proposed variable infiltration capacity (VIC) macro scale hydrological model. This model applies on hydrology of Mahanadi river basin and assesses land cover change impacts on stream flows at various locations along the river in the basin [202]. Kafle,et al., have proposed hydrologic engineering centre's hydrologic modelling system (HEC-HMS version 3.0.1) with GIS and this model predicted peak discharge ( $98 \%$ of observed value), on the same day [203]. Liu and Huagui, have designed gray dynamic analysis model and found that this model is used to predict hydrological factors and satisfactory performances are gained. So Prediction for the series has a certain accuracy and good results [204]. Longxi and Hong, have used one-dimensional hydrodynamics mathematical model and this model forecasts the changes of water level and flow ratio in high flow and low water periods [205]. Xu, et al., have utilized Support Vector Machine (SVM) based rainfall runoff models and It is found that both the process-based models TOPMODE and Xinanjiang model perform poorer compared with SVM model [206]. Deshmukh \& Ghatol,et al, have applied that Neural Network -based short-term runoff forecasting system, Jordan neural network model, Elman neural network model and have concluded that Jordan neural Network is performing better as compare to Elman neural network in forecasting runoff for $3 \mathrm{hrs}$ lead time [207]. $\mathrm{Li}$, et al., have proposed snow emission model, which reveals quantitatively and visually the snow depth inversion error due to multi-solution inversion [208].Wang and Qiu, have applied adaptive network based fuzzy inference system (ANFIS) model and found ANFIS model has better forecasting performance than artificial neural network model [209]. Wang, et al., have proposed support vector machine (SVM) model with chaotic genetic algorithm (CGA) and results is compared with the Neural Network 
performance. It is found that the SVM-CGA model can give good prediction performance and more accurate prediction results [210]. Ding,et al., have Combined Least Squares Support Vector Machine (LS-SVM) model based on empirical mode decomposition(EMD) and have concluded that this technique reduced maximal relative prediction error from $39.7 \%$ to $11.6 \%$.this model is better than linear regression model [211]. Liu,et al., have designed optimal subset regression and back propagation (OSR- BP) neural network model and the result shows that the stability of model is good and accuracy is satisfactory for long-term runoff prediction [212].Yan,et al., have compared between BPN model and RBFN model and found that the BP model has high accuracy and can be used to forecast runoff and the RBF model should be improved by treating the input value reasonably, choosing the data number suitably [213]. Liu,et al., have proposed Shuffled Complex Evolution Metropolis algorithm (SCEM-UA) and have concluded that the SCEM-UA is much better than that by GA [214]. Huang \& Tian, have applied multi-layer perception (MLP) with BPN, or simply as MLP-BPN model and Neural Network -based forecasting model components aimed to enhance modeling efficiency of interactive runoff forecasting [215]. Jizhong,et al., have designed Adaptive regulation ant colony system algorithm (ARACS) and RBF neural network combined to form ARACS-RBF hybrid algorithm.this method improves forecast accuracy and improves the RBF neural network generalization capacity; it has a high computational precision, and in $98 \%$ of confidence level the average percentage error is not more than 6\% [216]. Huang and Tian, have used support vector machine (SVM) based model with visual modelling system and found that the SVM shows slightly better performance both in the training and testing periods than the NEURAL NETWORK [217]. Pradhan,et al., have modified Soil conservation System (SCS) CN model with use of remote sensing and GIS technology and It is used for R-R estimation that considers parameter like slope, vegetation cover, area of watershed [218]

In the considerable contributions in 2011, Case study of Urban water resources Crisis, Shengtang,et al., have proposed a method Based o Stormwater utilization method and Stormwater utilization method is effective to alleviate water crises [219]. Fu and Wei, have proposed linear model formula With water resources network-node graph and it is used to the control amount of pollutants discharged into river [220]. Linke,et al., have applied conceptual rainfall runoff model based on statistical "black-box" models and this model is used provides high quality weather forecasts and flood warning systems [221].Wang, has designed digital management model and It plays important role in making flood control decision [222]. Ma, et al., have used combined model integrated chaos theory and wavelet analysis with support vector machine and this combined model is applicable to medium term and long term prediction. It is applicable for Neural Networkual runoff with small amplitudes with high forecasting accuracy [223]. Huaqil, et al., have integrated wavelet analysis and MNeural Network-Kendall (M-K) method with using discrete wavelet (DW) transform coefficients and this integration estimate the trend of time series, and apply a new road to analyze the multi-scale change character and short term forecast [224]. $\mathrm{Hu}$, et al., have used SVM (Support Vector Machine) model and compared SVM model with a previous NEURAL NETWORK model and it is found that the SVM model performed better [225]. İlker et al., have applied NEURAL NETWORK with coefficient of determination (R2) and root mean square error (RMSE) and found that the performance of the best Model using NEURAL
NETWORK [226]. Huang \& Wang, et al., have Proposed novel hybrid NN-GA(neural network - genetic algorithm ) and It showed that it increased the rainfall runoff forecasting accuracy more than any other model [227] Du and Zhu, have used universal Kriging forecast model based on geostatistics theory and It is applied to forecast Neural Networkual runoff [228]. Zhenmin, et al., have combined the neural network rainfall forecast model with genetic algorithm and GIS and found that the model efficiently improved forecast precision and speed [229]. Zhang and Wang, have applied wavelet- artificial fuzzy neural network ( ANFIS ) model and The result shows that, the prediction accuracy rises a lot, and it is fit to used in daily runoff predict [230]. Yan, et al., have integrated SVM model with rainfall and GIS factor and this model have been taken the rainfall and the vegetation coverage factors as input factors, could achieve a good effect [231]. Yanxun, et al., have developed runoff forecasting model using system theory with time series and it can be used for runoff forecasting and then for the groundwater resources evaluation [232]. Weilin, et al., have developed forecasting model for runoff, based on multivariate phase space reconstruction with neural network and partial least square method (PLS) and the result shows the multivariate model improves the prediction accuracy over univariate time series one [233]. Aiyun and Jiahai, have Combined the Wavelet analysis and Artificial Neural network (BP algorithm) and found that this model has a better capability of simulation for the process of monthly runoff and the model used to predict with a higher accuracy [234]. Zhang \& Lai, have proposed recurrent neural network based predictive model trained by a combination of particle swarm optimization and evolutionary algorithm. Proposed model ensure an accurate prediction on the urban runoff quantity. This provides an excellent prediction method for the stormwater runoff monitoring [235]. Chen, et al, have improved GIS-based TOPMODEL and found that the Improved TOPMODEL can be used for forecasting operations [236]. Chen \& $\mathrm{Li}$, have Combined HBV model with GIS and Improved HBV model can be applied to partial rain-storm flood forecast in small drainage basin [237]. Liang, et al., have Developed web-based system served as real-time rainfall-runoff forecast, which is capable of forecasting runoff generation, predicting rainfall, evaporation, calculating subsurface runoff and analyzing water balance [238]. Limlahapun, et al., have integrated flood forecasting model with the web-based system and found that it is improve flood monitoring, information distribution and an alert system [239]. Wu \& chau, have designed Neural Network, modular artificial neural network (M- Neural Network) with singular spectrum analysis (SSA) and the Neural Network R-R model coupled with SSA is more promising compare to Neural Network and LR models [240]. Wanga,et al., have used a predictive ocean atmosphere model for Australia (POAMA), conceptual rainfall-runoff model SIMHYD and POAMA forecasts as forcing improved forecasting skills significantly only for monthly forecasts, but not for three-monthly forecasts [241].

In 2012, Patil \& Patil, have reviewed the different forecasting algorithm algorithms of rainfall- runoff modelling and find out pros and cons of these algorithms and suggest framework of new algorithm for Rainfall runoff modeling which gives better water consumption [242]. Brocca, et al., two real data and two synthetic experiments have been carried out to assess the effects of assimilating soil moisture estimates into a two-layer rainfallrunoff model. By using the ensemble Kalman filter, both the surface- and root-zone soil moisture (RZSM) products derived by the advanced SCAT terometer (ASCAT) have been assimilated and the model performance on flood estimation is 
analyzed and The results of the synthetic experiments confirm the higher impact of the assimilation of root-zone soil moisture (RZSM) with respect to the surface soil moisture product [243]. Shengtang, et al., have developed a model Based on soil and water conservation activities (SWCA.) and the distributed hydrological models promised a good way to simulate the hydrological effects of SWCA [244]. Shah, et al., have applied hybrid approach of Possibilitic fuzzy C-mean and Interval type2 Fuzzy logic methods and this approach can help in plNeural Networking and reforming the agriculture structure, storm water management, runoff, and pollution control system, In addition, the accurate rainfall prediction [245]. the objective of minimizing energy consumption is designed by Xiao-lin, et al., have proposed a multi scenario model of hydrothermal optimal operation [246]. Bell,et al., have combined Support Vector Machine with sequential minimum optimization (SMO) algorithm with a RBF kernel function and this technique yield a relative absolute error $48.65 \%$ versus $63.82 \%$ for the human ensemble forecast, and optimize forecasts wet and dry years equally[247]. Li,et al., have proposed model Based on BPN algorithm and found that This technique deal the nonlinear hydrological series problems and provides a new idea to mid and long-term runoff forecast of reservoirs [248]. Zhang, et al., have applied one-dimensional movement model and this model can be used to forecast the debris flows. For certain rainfall intensity and terrain conditions [249]. Mittal, et al., have developed a dual (combined and paralleled) artificial neural network (D- Neural Network) and concluded that the D- Neural Network model performs better than the feed forward Neural Network (BPN) model [250]. Jingwen, et al., have used XXT model and found that the results show that XXT has better performance against the TOPMODEL and the Xinanjiang model [251].

In the noteworthy contributions in 2013, Chen,et al., have Studied of BPN and conventional regression analysis (CRA) and found that BPN perform better than the conventional regression analysis method [252]. Gebregiorgis, et al., have analysed precipitation estimation from remotely sensed information using artificial neural networks is better than 3B42RT and climate prediction center morhing technique (CMORPH) technique [253]. Phuphong and Surussavadee, have applied Neural Network based runoff forecasting model and Results show good forecast accuracy and useful forecasts 12 hours in advance [254]. Zhang, et al., have studied study, the deterministic Ensemble Kalman Filter - Ensemble Square Root Filter was coupled with a widely used conceptual rainfall-runoff model to assimilate streamflow data from either in-situ or remote sensing sources to update all the internal states in the model and result show that the use of satellite data for improving flood forecasting worldwide [255]. Patil, et al., have reviewed the different forecasting algorithms. Neural Network, FL, GA of rainfall- runoff modelling and have concluded that can be combined fuzzy logic and Neural Network together and find out The better result and use these result for prediction [256]. Robertson, et al.,have investigated whether a hybrid seasonal forecasting system that uses the output of a dynamic hydrological model as a predictor in a statistical forecasting and found that this approach can lead to more skilful forecasts [257]. Vleeschouwer and Pauwels, have examined indirect calibration of a rainfall-runoff model and have shown that a certain potential exists for indirect calibration of a rainfall-runoff model (in particular indirect spectral calibration) in the case of spatial, temporal and spatio-temporal gauging divergence in ungauged catchments [258]. Ramana, et al., have combined the wavelet technique with Neural Network and found that the performances of wavelet neural network models are more effective than the
Neural Network models [259].

\subsection{Spatial Interpolation}

In much science and engineering practice today, there is an increasing demand for techniques which are capable of interpolating irregularly scattered data distributed in space. These techniques have many applications including rainfall estimation. Mathematically, the general model for spatial interpolation of values $\mu$ in a surface ' $R$ ' can be expressed as:

$$
\varphi=f\left(x, y, z, \mu, v_{1}, v_{2}, \ldots, v_{\mathrm{n}}\right)
$$

Where, $(x, y, z)$ is a geo-coordinate location and $v_{1}, v_{2}, \ldots$, vn are additional variables. In Neural Network model dependent variable $\mu$ can be expressed as rainfall variable, $x, y, z$ are geocoordinate (latitude, longitude, and altitude), and $v_{1}, v_{2}, \ldots, v_{\mathrm{n}}$ can be defined as random weights to be optimized. In this section, contributions from the year 50 years have been reviewed.

It is found that, there are several interpolation methods for solving the above problem have been used. Techniques such as geostatistical co-kriging (Journel and Huijbregts, 1978) and Neural Network (Hornik et al., 1987) are common. Goovaerts, 1997, Demyanov, 1998), S. van der Heijden has suggested four methods for spatial interpolation including Neural Network in their work [262-65]. Huang et al. (1998), demonstrated the use of dynamic fuzzy-reasoning-based function estimator (DFFE) to interpolate rainfall data in a case study in Switzerland [266a and b]. The functional parameters are also optimized by genetic algorithms (GA). Ricardo and Palutikof, 1999, have successfully applied Neural Network technique for simulation of daily temperature for climate change scenarios over Portugal [267] Guhathakurta, 1998, has applied hybrid Neural Network in prediction of Indian monsoon rainfall and has found very significant results almost more than $85 \%$ correctness. Guhathakurta, 1999, applied this Neural Network method effectively in prediction of surface Ozone which is very dynamic and unpredictable in nature for very smaller geographical earth region. He has also contributed extremely significant finding in the year of 2000 and 2006 with the similar Neural Network methods especially for climate variable prediction [268]. Rajeevan et al. (2000) have given a power regression based long-rang monsoon rainfall forecasting system for peninsular Indian region [269]. However, Guhathakurta (2006) and Karmakar et al. (2008) have found that, the NEURAL NETWORK method is better evaluated over the statistical technique for the same [270]. Snell, 2000 has found a new method for the spatial interpolation of daily maximum surface air temperatures [271]. This new method uses Neural Network to generate temperature estimates at eleven locations given information from a lattice of surrounding locations. The out-of-sample performance of the Neural Networks is evaluated relative to a variety of benchmark methods (spatial average, nearest neighbor, and inverse distance methods). He has found that, the Neural Network approach is superior both in terms of predictive accuracy and model encompassing. Antonić et al. (2001) have described Spatio-temporal interpolation of climatic variables over large region of complex terrain using neural networks. Presented interpolation models provide reliable, both spatial and temporal estimations of climatic variables, especially useful for dendroecological analysis [272]. Rigol et al. (2001) have described spatial interpolation of daily minimum air temperature using a feed-forward back-propagation neural network [273]. Simple network configurations were trained to predict minimum temperature using as inputs: (1) date and terrain variables; (2) temperature observations at a number of neighbouring locations; (3) date, terrain variables and 
neighbouring temperature observations. This is the first time that trend and spatial association are explicitly considered together when interpolating using an Neural Network. Koike et al. (2001) suggested an interpolation method based on a multilayer neural network (MNN), has been examined and tested for the data of irregular sample locations, he found that, the main advantage of MNN is in that it can deal with geographical data with nonlinear behavior [274]. Bryan and Adams (2002) have successfully applied in interpolation of Neural Networkual Mean Precipitation and Temperature Surfaces for China [275]. Li (2002) have suggested Neural Network models could be used to accurately estimate these weather variables. In this study, Neural Network -based methods were developed to estimate daily maximum and minimum air temperature and total solar radiation for locations in Georgia. Observed weather data from 1996 to 1998 were used for model development, and data from 1999 to 2000 were used for final Neural Network model evaluation, Iseri et al. (2002) have found that, the Neural Network in Medium Term Forecasting of Rainfall over Indian region is sufficiently suitable [276]. Silva 2003 has successfully applied Neural Network technique for special interpolation of temperature variable carried out in the Austrian Central Institute of Meteorology and Geodynamics - ZAMG, on the scope of the COST Action 719. This work focuses on the capabilities of Neural Networks used in the spatial interpolation of some climate variables showing the advantages and disadvantages [277]. The application of an Neural Network on the Austria mean air temperature distribution for August has produced good results, explained by the strong altitude dependency of this parameter. Timonin and Savelieva, 2005, have described another application for spatial prediction of radioactivity using GRNN. Guhathakurta 2006, Karmakar et al. $(2008,2009)$ have found that, the Rumelhart,1986 learning algorithm based Neural Network model can be also appropriate for long-range monsoon rainfall prediction over very smaller geographical region. Attorre et al. (2007) have compared three methods that have been proved to be useful at regional scale: 1 - a local interpolation method based on de-trended inverse distance weighting (D-IDW), 2 - universal kriging (i.e. simple kriging with trend function defined on the basis of a set of covariates) which is optimal (i.e. BLUP, best linear unbiased predictor) if spatial association is present, 3 - multilayer neural networks trained with back-propagation (representing a complex nonlinear fitting) and found Neural Network interpolator has proven to be more efficient [278]. Chattopadhyay, and Chattopadhyay, 2008, have found that, the Neural Network for Indian Rainfall prediction using Neural Network is suitable and especially he suggested architecture of hidden layer of the network [279]. Ultimately it has been established that the eleven hidden nodes three-layered neural network has more efficacy than asymptotic regression in the present forecasting task. Hung, 2009, presented Neural Network technique to improve rainfall forecast performance over Bangkok Thailand. Mendes and Marengo, 2010 have developed and tested a novel type of statistical downscaling technique based on the Artificial Neural Network, applied of the climate change [280]. The Neural Network used here are based on a feed forward configuration of the multilayer perception that has been used by a growing number of authors. Sivapragasam et al. (2010) have found that, the interpolation of Hydrological variable such as rainfall, ground water level, etc for Tamil Nadu state India using Neural Network is useful [282]. However, 18 stations data samples have been used to develop Neural Network. It is observed that, by more stations, this methodology can produce better result. Ghazanfari et al. (2011), have suggested a new model PERSINEURAL Neural
Network (Precipitation estimation from remotely sensed information using artificial neural network) model works based on the Neural Network system which uses multivariate nonlinear input-output relationship functions to fit local cloud top temperature to pixel rain rates. In this study, PERSINEURAL Neural Network model and two interpolation methods (Kriging \& IDW) are employed to estimate precipitation cover for NorthKhorasan between the years 2006 until 2008. He has found better correlation between PERSINEURAL Neural Network output and station data than the other two interpolation methods. While correlation coefficient for Kendal's test is 0.805 between model and Bojnord Station data, this coefficient is 0.488 and 0.565 for Kriging method [283]

By review of very significant contributions of all the authors from 1978 to 2012, it is concluded that, Neural Network method is sufficiently suitable for identifying internal dynamics of rainfall variables, as well as significant to develop an association between dependent and independent variable in prediction as well as interpolation. However, it is also found that, the selection of appropriate architecture of Neural Network is exceptionally tricky in addition to its training. Selection of its parameters, i.e., number of input vectors, hidden layers, and hidden neurons is again very dynamic depending on data series. Training of Neural Network is also again enormous challenging task. It is found that, the selection of parameters and training process may cause of temporal nervousness as well. To train the network, how many epochs are required, how to obtain global minima during error minimization process (i.e., training) is not often clearly available in the literature although very wide range of applications of NEURAL NETWORK has been found. No author has found who have evidently described these features in their offerings.

\section{RESULTS AND DISCUSSIONS}

Two major framework of Neural Network have been found by the above literature review and those are adequately appropriate to predict chaotic behavior of climate variables are discussed in the following subsections-

Lee et al., 1998, have found that RBFN produced good prediction while the linear models poor prediction [23]. After a study of RBFN, Chang et al., 2001, have found that it is a suitable technique for a rainfall runoff model for three hours ahead floods forecasting [34]. In 2004 Maqsood et al., have found that HFM is relatively less accurate and RBFN is relatively more reliable for the weather forecasting problems and in comparison the ensembles of neural networks produced the most accurate forecast [42]. Exploring the new concept, soft computing models based on RBFN for 24-h weather forecasting, Maqsood et al., have concluded that the RBF neural network produces the most accurate forecasts compared to the MLP, ERNN and HFM [54]. As we know that neural network can applied for most of the prediction aspects, Nekoukar et al., 2010, have used radial RBFN for financial time-series forecasting, and the result of their experiment shows the feasibility and effectiveness [80]. Patil and Ghatol, 2010, have used various Neural Network topologies such as radial RBF and multilayer perceptron with Levenberg Marquardt and momentum learning rules for predicting rainfall using local parameters and they found the topologies fit for the same task [85]. Joshi and Patel, 2011, have put in a review report on Rainfall-Runoff modeling using Neural Network, in the same study they have reviewed three neural network methods, Feed Forward Back Propagation (FFBP), RBFN and Generalized Regression Neural Network (GRNN) and they have seen that GRNN flow estimation 
performances were close to those of the FFBP, RBF and MLR [95]. It is observed that many of the scientists have used Neural Network and various Neural Network models for forecasting Rainfall, Temperature, Wind and Flood etc., El-Shafie et al., 2011, have compared and studied Dynamic Vs Static neural network models for rainfall forecasting, they have developed AI based forecasting architectures using Multi-Layer Perceptron Neural Networks (MLPNN), Radial Basis Function Neural Networks (RBFNN) and Adaptive Neuron-Fuzzy Inference Systems (ANFIS), finally they concluded that the dynamic neural network namely IDNN could be suitable for modeling the temporal dimension of the rainfall pattern, thus, provides better forecasting accuracy [101]

Lekkas et al., 2004 have used a multilayer back propagation network and found that BPNN will not always find the correct weight and biases fort the optimum solution, whereas their results supported the hypothesis that Neural Networks can produce qualitative forecast. A 7 hour ahead forecast in particular proves to be of fairly high precision, especially when an error prediction technique is introduced to the Neural Network model [44]. In coastal areas it is an enormous prediction of tidal level, Tsong-Lin Lee, 2004, has predicted long-term tidal level using back propagation neural network, as compare to conventional harmonic method, he concluded that back-propagation neural network mode also efficiently predicts the long-term tidal levels [49]. On the basis of humidity, dew point and pressure in India, Enireddy et al., 2010, have used the back propagation neural network model for predicting the rainfall. In the training they have obtained $99.79 \%$ of accuracy and $94.28 \%$ in testing. From these results they have concluded that rainfall can predicted in future using the same method [88]. Joshi and Patel, 2011, have put in a review report on RainfallRunoff modeling using Neural Network, in the same study they have reviewed three neural network methods, Feed Forward Back Propagation (FFBP), Radial Basis Function (RBF) and Generalized Regression Neural Network (GRNN) and they have seen that GRNN flow estimation performances were close to those of the FFBP, RBF and MLR [95]. The temperature has a great effect in forecasting rainfall Amanpreet Kaur, and Harpreet Singh, 2011, have tested Artificial Neural Network in forecasting minimum temperature, they have used multi layer perceptron architecture to model the forecasting system and back propagation algorithm is used to train the network. They found that minimum temperature can be predicted with reasonable accuracy using Neural Network model [98]. Geetha and Selvaraj, 2011, have predicted Rainfall in Chennai using back propagation neural network model, by their research the mean monthly rainfall is predicted using Neural Network model. The model can perform well both in training and independent periods [102]. Predicting groundwater level is somehow a difficult task now a day because it varies place to place and round the globe, Mayilvaganan, and Naidu, 2011, have attempted to forecast groundwater level of a watershed using Neural Network and Fuzzy Logic. A three-layer feed-forward Neural Network was developed using the sigmoid function and the back propagation algorithm. Now it has been observed that NEURAL NETWORKs perform significantly better than Fuzzy Logic [105]. El-shafie et al., 2011, have tried to use neural network and regression technique for rainfall-runoff prediction finally they concluded that the results showed that the feed forward back propagation Neural Network (NEURAL NETWORK) can describe the behaviour of rainfall-runoff relation more accurately than the classical regression model [106]. Sawaitul et al., have presented an approach for classification and prediction of future weather using back propagation algorithm, and discussed different models which were used in the past for weather forecasting, finally the study concludes that the new technology of wireless medium can be used for weather forecasting process. It also concludes that the Back Propagation Algorithm can also be applied on the weather forecasting data. Neural Networks are capable of modeling a weather forecast system [110].

\section{CONCLUSIONS}

During a concentrated study of applications of various architectures of Neural Network it has been obtained that the BPN and RBF are the methods which have been used by most of the researchers and the result of their test found to be satisfactory without any scientific argument. In general it has been observed that out of various prediction techniques such as statistical and numerical modeling, over the meteorological data, Neural Network is proved to be an appropriate technique undoubtedly for forecasting various climate conditions. In 2014, Karmakar et al. explained that the BPN in identification of internal dynamics of chaotic motion is found to be a perfect and appropriate in forecasting various natural phenomena. However, selection of its parameters likes, Number of input vectors (n), Number of hidden layers (m), Number of neurons in hidden layers (p), Number of output neurons (y), Weights and biases, Learning rate $(\alpha)$, Momentum factors $(\mu)$ seems crucial during design time. Especially for chaos prediction, no authors have provided optimum value of these parameters. Also during the training process through the algorithm developed by (Rumelhart et al., 1986) it is found that, a high learning rate $(\alpha)$ leads to rapid learning but the weights may oscillate, while a lower value of $\alpha$ leads to slower learning process in weight updating. Identification of an appropriate value of $\alpha$ maintaining a higher learning process needs special attention of the researchers in this area. The main reason of the momentum factor $(\mu)$ is to accelerate the convergence of error during the training. It is the most complicated and experimental task to select appropriate value of ' $\alpha$ ' and ' $\mu$ ' during the training process of BPN as well. They identified these parameters to identify internal dynamics of monsoon rainfall data time series through deterministic forecast. It is noted that, BPN parameters values may differ for other problems. Thus, optimization of BPN parameters is very essential and consequently their optimum values should be chosen cautiously through experiments only. Finally it can be observed that the BPN model can be practical to prediction of climate modeling, however, required superiority to select its parameters like vijs, wijs, v0, w0, m1, m2, n, p, $f(\mathrm{x}), \mathrm{e}, \mathrm{yk}, \alpha$, and $\mu$ is vital. Thus a careful experimentation is suggested before apply the NEURAL NETWORK model in chaos prediction and interpolation.

\section{REFERENCES}

[1] Walker, G. T., 1923, "Correlation in Seasonal Variations of Weather, III. A Preliminary Study of World Weather". Mem. India Meteorol. Dep., XXIV, 75-131.

[2] Walker, G. T., 1924, "Correlation in Seasonal Variations of Weather, IV. A Further Study of World Weather". Mem. India Meteorol. Dep., XXIV, 275-332.

[3] Gowariker, V., Thapliyal, V., Sarker, R. P., Mandal, G. S. and Sikka, D. R., 1989, "Parametric and Power Regression Models: New Approach to Long Range Forecasting of Monsoon Rainfall in India”. Mausam, 40, 115- 122.

[4] Gowariker, V., Thapliyal, V., Kulshrestha, S. M., Mandal, G. S., Sen Roy, N., and Sikka, D. R., 1991, "A Power Regression Model for Long Range Forecast of Southwest 
Monsoon Rainfall over India”. Mausam, 42, 125-130.

[5] Thapliyal, V., and Kulshrestha, S. M., 1992, "Recent Models for Long Range Forecasting of Southwest Monsoon Rainfall over India”. Mausam, 43, 239-248.

[6] Thapliyal, V., 1997, "Preliminary and Final Long Range Forecasts for Seasonal Monsoon Rainfall over India". J. Arid Environ., 36, 385-403.

[7] Rajeevan, M., Guhathakurta, P. and Thapliyal, V., 2000, "New Models for Long Range Forecasting of Monsoon Rainfall over Northwest and Peninsular India". Meteorol. Atmos. Phys., 73, 211-225.

[8] Rajeevan M., 2001, "Prediction of Indian Summer Monsoon: Status, Problems and Prospects". Current Science, 81, 1451-1457.

[9] Thapliyal, V., and Rajeevan, M., 2003, "Updated Operational Models for Long-Range Forecasts of Indian Summer Monsoon Rainfall”. Mausam, 54, 495-504.

[10] Rajeevan, M., Pai, D.S., Dikshit, S.K., and Kelkar, R. R., 2004, "IMD's New Operational Models for Long-Range Forecast of Southwest Monsoon Rainfall over India and Their Verification for 2003", Current Science, 86 (3), 422431.

[11] Guhathakurta, P., 2000, "New Models for Long Range Forecasts of Summer Monsoon Rainfall over North West and Peninsular India”, Meteor. \& Atomos. Phys.,73 (3), 211-255.

[12] Guhathakurta, P., Rajeevan, M., and Thapliyal, V., 1999, "Long Range Forecasting Indian Summer Monsoon Rainfall by Hybrid Principal Component Neural Network Model", Meteorology and Atmospheric Physics, SpringerVerlag, Austria.

[13] Parthasarathy, B., Rupa Kumar, K., and Munot, A. A., 1991, "Evidence of Secular Variations in Indian Summer Monsoon Rainfall Circulation Relationships". J. Climate, 4, 927-938.

[14] Hastenrath, S., and Greischar, L., 1993, "Changing Predictability of Indian Monsoon Rainfall Anomalies". Proc. Indian Acad. Sci. (Earth Planet. Sci.), 102, 35-47.

[15] Guhathakurta P., (2006), "Long-Range Monsoon Rainfall Prediction of 2005 for the Districts and Sub-Division Kerala with Artificial Neural Network", Current Science, 90(6), pp-773-779.

[16] Krishnamurthy, V., and Kinter, J. L., 2002, "The Indian Monsoon and its Relation to Global Climate Variability". Global Climate - Current Research and Uncertainties in the Climate System (eds Rodo, X. and Comin, F. A.), 186-236.

[17] Krishnamurthy, V., and Kirtman, B. P., 2003, "Variability of the Indian Ocean: Relation to Monsoon and ENSO". Q. J. R." Meteorol. Soc., 129, 1623-1646

[18] Sahai, A. K., Grimm, A. M., Satyan. V. and Pant, G. B., 2002, "Prospects of Prediction of Indian Summer Monsoon Rainfall using Global SST Anomalies". IITM Research Report No. RR-093.

[19] Guhathakurta, P., 1999, "Long Range Forecasting Indian Summer Monsoon Rainfall By Principle Component Neural Network Model”, Meteor. \& Atomos. Phys., 71, 255-266.
[20] Guhathakurta, P., 1998, “A Hybrid Neural Network Model for Long Range Prediction of All India Summer Monsoon Rainfall", Proceedings of WMO international workshop on dynamical extended range forecasting, Toulouse, France, November 17-21, 1997, PWPR No. 11, WMO/TD. 881, pp $157-161$

[21] Basu Sujit \& Andharia H I, 1992, "The Chaotic time series of Indian Monsoon rainfall and its prediction", Proc. Indian Acad. Sci., Vol. 101, No. 1, pp 27-34.

[22] Chow T. W. S. and Cho S. Y., 1997, "Development of a Recurrent Sigma-Pi Neural Network Rainfall Forecasting System in Hong Kong”, Springer-Verlag, pp. 66-75.

[23] Lee Sunyoung, Cho Sungzoon, Wong Patrick M., 1998 "Rainfall Prediction Using Artificial Neural Networks", Journal of Geographic Information and Decision Analysis, vol. 2, no. 2, pp. $233-242$.

[24] Hsieh, W.H., and Tang, B., 1998, "Applying Neural Network Models to Prediction and Analysis in Meteorology and Oceanography". Bull. Amer. Met. Soc., $79,855-1870$

[25] Dawson Christian W., Wilby Robert, "An artificial neural network approach to rainfall runoff modeling", 1998, Hydrological Sciences—Journal, 43(1), pp. 47-66.

[26] Guhathakurta1 P., Rajeevan2 M., and Thapliyal2 V., 1999 , "Long Range Forecasting Indian Summer Monsoon Rainfall by a Hybrid Principal Component Neural Network Model", Meteorol. Atmos. Phys., 71, pp. 255-266.

[27] Ricardo, M., Trigo, Jean, P., Palutikof, 1999, "Simulation of Daily Temperatures for Climate Change Scenarios over Portugal: A Neural Network Model Approach", University of East Anglia, Norwich, NR4 7TJ, United Kingdom, climate research (Clim., Res.), 13, 45-59, 1999.

[28] Jones, C., Peterson, P., 1999, “A New Method for Deriving Ocean Surface Specific Humidity and Air Temperature: An Artificial Neural Network Approach", J. Applied Meteorology, American Meteorological Society, 38, 1229. 1245 .

[29] Guhathakurta, P., 1999, "A Short Term Prediction Model for Surface Ozone At Pune: Neural Network Approach", Vayu mandal, Special issue on Asian monsoon and pollution over the monsoon environment, 29(1-4), 355-358.

[30] Guhathakurta, P., 1999, "A Neural Network Model for Short Term Prediction of Surface Ozone at Pune", Mausam, 50(1), 91-98.

[31] Toth E. *, Brath A., Montanari A., 2000, "Comparison of short-term rainfall prediction models for real-time flood forecasting", Journal of Hydrology, Elsevier, 239, pp. 132147.

[32] Luk Kin C, Ball J. E. and Sharma A., 2001, “An Application of Artificial Neural Networks for Rainfall Forecasting", 33, pp. 883-699.

[33] Michaelides Silas Chr,*, Pattichis Constantinos S. and Kleovouloub Georgia, 2001, "Classification of rainfal variability by using artificial neural networks", International Journal Of Climatology, pp. 1401-1414.

[34] Chang Fi-John, Liang Jin-Ming, and Chen YenChang,2001, "Flood Forecasting Using Radial Basis 
Function Neural Networks", IEEE Transactions On Systems, Man, And Cybernetics, vol. 31, no. 4, pp. 530535 .

[35] Brath A., Montanari A. and Toth E., 2001, "Neural networks and non-parametric methods for improving ealtime flood forecasting through conceptual hydrological models", Hydrology and Earth System Sciences, 6(4), pp. 627-640.

[36] Rajurkar M. P., Kothyari U. C., Chaube U. C., 2002, "Artificial neural networks for daily rainfall-runoff modelling”, Hydrologkal Sciences-Journals, 47(6), pp. 865877.

[37] Harun Sobri, Nor Irwan Ahmat \& Mohd. Kassim Amir Hashim, 2002, "Artificial neural network model for rainfall-runoff relationship", Journal Technology, Malaysia, pp. 1-12.

[38] Iseri, Y. G. C., Dandy, R., Maier, A., Kawamura, and Jinno, K., 2002, "Medium Term Forecasting of Rainfall Using Artificial Neural Networks", Part 1 background and methodology, Journal of Hydrology , 301 (1-4), 1834-1840.

[39] Silva, A. P., 2003, "Neural Networks Application to Spatial Interpolation of Climate Variables", Carried Out By, STSM on the Framework of COST 719 ZAMG, Vienna 6-10 October 2003.

[40] Snell., Seth, E., Gopal, Sucharita, KaufmNeural Network, Robert, K., 2003, "Spatial Interpolation of Surface Air Temperatures Using Artificial Neural Networks: Evaluating Their Use for Downscaling GCMs", Journal of Climate, 13 (5), 886-895.

[41] Blender, R., 2003, "Predictability Study of the Observed and Simulated European Climate using Linear Regression", Q. J. R. Meteorol. Soc. (2003), 129, 2299-2313.

[42] Maqsood Imran, Khan Muhammad Riaz, Abraham Ajith, 2004, Neural Comput \& Applic, 13, pp. 112-122.

[43] Pasero Eros, Moniaci Walter, 2004, “Artificial Neural Networks for Meteorological Nowcast", IEEE international Conference,

[44] Lekkas D.F.,* Onof1 C., Lee1 M. J., Baltas2 E.A., 2004, "Application of artificial neural networks for flood forecasting", Global Nest, Vol 6, No 3, pp 205-211.

[45] Shu Chang and Burn Donald H., 2004, "Artificial neural network ensembles and their application in pooled flood frequency analysis", Water Resources Research, vol. 40.

[46] Nayaka P.C.,*, Sudheerb K.P.,1Ranganc, D.M.,2, Ramasastrid K.S.,3, 2004, "A neuro-fuzzy computing technique for modeling hydrological time series", Journal of Hydrology, Elsevier, 291, pp. 52-66.

[47] Wu Jy S., P.E., ASCE1 M.; Han2 Jun; Neural Networkambhotla3 Shastri; and Scott Bryant4, 2004, "Artificial Neural Networks for Forecasting Watershed Runoff and Stream Flows", Journal Of Hydrologic Engineering, 216.

[48] Abdel-Aal R.E. *, 2004, "Hourly temperature forecasting using abductive networks", Elsevier, 17, pp. 543-556.

[49] Lee Tsong-Lin, 2004, "Back-propagation neural network for long-term tidal predictions", Elsevier, 31, pp. 225-238.
[50] Chaudhuri Sutapa, Chattopadhyay Surajit, 2005, “ Neuro-computing based short range prediction of some meteorological parameters during the pre-monsoon season", Springer-Verlag, 9, pp. 349-354.

[51] Lin Gwo-Fong * and Chen Lu-Hsien, 2005, "Application of an artificial neural network to typhoon rainfall forecasting", Hydrological Processes, 19, pp. 1825-1837.

[52] Vandegriff Jon *, Wagstaff Kiri, George Ho, Plauger Janice, 2005, "Forecasting space weather: Predicting interplanetary shocks using neural networks", Elsevier, vol 36, pp. 2323-2327.

[53] KISI Ozgur, 2005, "Daily River Flow Forecasting Using Artificial Neural Networks and Auto-Regressive Models", Turkish J. Eng. Env. Sci., vol 29, pp. 9 - 20.

[54] Maqsood Imran, Khan Muhammad Riaz, Huang Guo H., Abdalla Rifaat, 2005, "Application of soft computing models to hourly weather analysis in southern Saskatchewan, Canada", Elsevier, vol 18, pp. 115-125.

[55] Somvanshi V.K., Pandey O.P., Agrawal P.K., Kalanker1 N.V., Prakash M.Ravi and Chand Ramesh, 2006, "Modelling and prediction of rainfall using artificial neural network and ARIMA techniques", J. Ind. Geophys. Union, Vol.10, No.2, pp.141-151.

[56] Srikalra Niravesh and Tanprasert Chularat, 2006, "Rainfall Prediction for Chao Phraya River using Neural Networks with Online Data Collection”, Malaysia, pp. 13-15.

[57] Kumarasiri A.D.and Sonnadara D.U.J., 2006, "Rainfall Forecasting: An Artificial Neural Network Approach", Proceedings of the Technical Sessions, vol 22, pp. 1-13.

[58] Kumar D. Nagesh, Reddy M. Janga and Maity Rajib, 2006, "Regional Rainfall Forecasting using Large Scale Climate Teleconnections and Artificial Intelligence Techniques", Journal of Intelligent Systems, Vol. 16, No.4, pp. 307-322.

[59] Guhathakurta, P., 2006, "Long-Range Monsoon Rainfall Prediction of 2005 for the Districts and Sub-Division Kerala With Artificial Neural Network", Current Science, 90 (6), pp-773-779.

[60] Bustami Rosmina, 1 BessaihNabi, Charles Bong, Suhaila Suhaili, 2007, "Artificial Neural Network for Precipitation and Water Level Predictions of Bedup River", International Journal of Computer Science, vol 34:2.

[61] Paras, Mathur Sanjay, Kumar Avinash, and Chandra Mahesh, 2007, "A Feature Based Neural Network Model for Weather Forecasting", World Academy of Science, Engineering and Technology, vol 34, pp. 66-73.

[62] Hayati Mohsen, and Mohebi Zahra, 2007, "Application of Artificial Neural Networks for Temperature Forecasting", World Academy of Science, Engineering and Technology, vol 28, pp. 275-279.

[63] Morid Saeid, Smakhtin Vladimir and Bagherzadeh K., 2007, "Drought forecasting using artificial neural networks and time series of drought indices", Royal Meteorological Society, vol. 27, pp. 2103-2111.

[64] Hayati Mohsen, and Shirvany Yazdan, 2007, "Artificial Neural Network Approach for Short Term Load Forecasting for Illam Region”, World Academy of Science, Engineering and Technology, vol. 28, pp. 280-284. 
[65] Lucio P. S., Conde F. C., Cavalcanti I. F. A., Serrano A. I., Ramos A. M., and Cardoso A. O., 2007, "Spatiotemporal monthly rainfall reconstruction via artificial neural network - case study: south of Brazil", Advances in Geosciences, vol. 10, pp. 67-76.

[66] HartmNeural Network, Heikea * Becker Stefanb and Kinga Lorenz, 2007, "Predicting summer rainfall in the Yangtze River basin with neural networks", Royal Meteorological Society.

[67] Aliev R. A., Fazlollahi B., Aliev R. R., Guirimov B., 2008, "Linguistic time series forecasting using fuzzy recurrent neural network", Soft Comput, vol. 12, pp. 183-190.

[68] Chattopadhyay Surajit and Chattopadhyay Goutami, 2008, "Identification of the best hidden layer size for three layered neural net in predicting monsoon rainfall in India", Journal of Hydroinformatics, vol. 10(2), pp. 181-188.

[69] Hung N. Q., Babel M. S., Weesakul S., and Tripathi N. K., 2008, "An artificial neural network model for rainfall forecasting in Bangkok, Thailand", Hydrology and Earth System Sciences, vol. 5, pp. 183-218.

[70] Aytek Ali, Asce M and Alp Murat, 2008, "An application of artificial intelligence for rainfall-runoff modeling", J. Earth Syst. Sci., vol. 117, No. 2, pp. 145-155.

[71] Chattopadhyay Goutami, Chattopadhyay Surajit, Jain Rajni, 2008, "Multivariate forecast of winter monsoon rainfall in India using SST anomaly as a predictor: Neurocomputing and statistical approaches",

[72] Win Khaing Mar and Thu Naing Thinn, 2008, "Optimum Neural Network Architecture for Precipitation Prediction of Myanmar", World Academy of Science, Engineering and Technology, vol. 48, pp. 130-134.

[73] Karmakar Sanjeev et al., 2008, "Development of a Satellite Based Agriculture Meteorological Information System (AGRIMETCast) in the Context of Remote Places of Chhattisgarh Using Remote Sensing Data", India Society of Remote Sencing, Ahmedabad, India., SAC (ISRO)

[74] Karmakar Sanjeev et al., 2008, "Development of Artificial Neural Network Models for Long-Range Meteorological Parameters Pattern Recognition over the Smaller Scale Geographical Region", IEEE Computer Society, Washington, DC, USA., 8-10 Dec. 2008, pp.1 - 6.

[75] Hocaoglu Fatih O., Oysal Yusuf, Kurban Mehmet, 2009, "Missing wind data forecasting with adaptive neuro-fuzzy inference system", Springer-Verlag London, vol. 18, pp. 207-212.

[76] Solaimani Karim, 2009, "Rainfall-runoff Prediction Based on Artificial Neural Network (A Case Study: Jarahi Watershed)", American-Eurasian J. Agric. \& Environ. Sci., vol. 5(6), pp. 856-865.

[77] KOŠCAK Juraj, JAKŠA Rudolf., SEPEŠI Rudolf, SINCÁK Peter., 2009, "Weather forecast using Neural Networks", 9th Scientific Conference of Young Researchers

[78] Karamouz M. Fallahi M, Nazif S. and Farahani M. Rahimi, 2009, "Long Lead Rainfall Prediction Using Statistical Downscaling and Arti cial Neural Network Modeling", Transaction A: Civil Engineering, Vol. 16, No. 2, pp. 165172.
[79] Widjanarko Bambang Otok, Suhartono, 2009, "Development of Rainfall Forecasting Model in Indonesia by using ASTAR, Transfer Function, and ARIMA Methods", European Journal of Scientific Research, Vol.38 No.3, pp.386-395.

[80] Nekoukar Vahab, Taghi Mohammad, Beheshti Hamidi, 2010, "A local linear radial basis function neural network for financial time-series forecasting", Springer Science, vol. 23 , pp. 352-356.

[81] Weerasinghe H.D.P.,. Premaratne H.L and Sonnadara D.U.J., 2010, "Performance of neural networks in forecasting daily precipitation using multiple sources", J.Natn.Sci.Foundation Sri Lanka, vol. 38(3), pp. 163-170.

[82] Luenam Pramote, Ingsriswang Supawadee, Ingsrisawang Lily, Aungsuratana Prasert, and Khantiyanan Warawut, 2010, "A Neuro-Fuzzy Approach for Daily Rainfall Prediction over the Central Region of Thailand", ISSN 2010, vol. 1.

[83] Wu C. L.,. Chau1 K. W, and Fan C., 2010, "Prediction of Rainfall Time Series Using Modular Artificial Neural Networks Coupled with Data Preprocessing Techniques", Journal of Hydrology, Vol. 389, No. 1-2, pp. 146-167.

[84] Nastos Panagiotis, Moustris Kostas, Larissi IoNeural Networka, and Paliatsos Athanasios, 2010, "Rain intensity forecast using Artificial Neural Networks in Athens, Greece", Geophysical Research Abstracts, Vol. 12.

[85] Patil C. Y. and Ghatol A. A., 2010, "Rainfall forecasting using local parameters over a meteorological station: an artificial neural network approach", International J. of Engg. Research \& Indu. Appls, Vol.3, No. II, pp 341-356.

[86] Tiron Gina, and Gosav Steluţa, 2010, "The july 2008 rainfall estimation from BARNOVA WSR-98 D Radar using artificial neural network", Romanian Reports in Physics, Vol. 62, No. 2, pp. 405-413.

[87] Goyal Manish Kumar, Ojha Chandra Shekhar Prasad, 2010, "Analysis of Mean Monthly Rainfall Runoff Data of Indian Catchments Using Dimensionless Variables by Neural Network", Journal of Environmental Protection, vol. 1, pp. 155-171.

[88] Vamsidhar Enireddy Varma K.V.S.R.P..Sankara Rao P satapati Ravikanth, 2010, "Prediction of Rainfall Using Backpropagation Neural Network Model", International Journal on Computer Science and Engineering, Vol. 02, No. 04, pp. 1119-1121.

[89] Haghizadeh Ali, Teang shui Lee, Goudarzi Ehsan, 2010, "Estimation of Yield Sediment Using Artificial Neural Network at Basin Scale", Australian Journal of Basic and Applied Sciences, vol. 4(7), pp. 1668-1675.

[90] Subhajini A . C. and Joseph Raj V., 2010, “Computational Analysis of Optical Neural Network Models to Weather Forecasting", International Journal of Computer Science Issue, Vol.7, Issue 5, pp. 327-330.

[91] Omer Faruk Durdu, 2010, "A hybrid neural network and ARIMA model for water quality time series prediction.", Elsevier, vol 23, pp. 586-594

[92] Soman Saurabh S, Zareipour Hamidreza, Malik Om, and Mandal Paras, 2010, "A Review of Wind Power and Wind Speed Forecasting Methods With Different Time 
Horizons".

[93] Khalili Najmeh, Khodashenas Saeed Reza, Davary Kamran and Karimaldini Fatemeh, 2011, "Daily Rainfall Forecasting for Mashhad Synoptic Station using Artificial Neural Networks", International Conference on Environmental and Computer Science, vol.19, pp. 118-123.

[94] Pan Tsung-Yi, Yang Yi-Ting, Kuo Hung-Chi, Tan YihChi, Lail Jihn-Sung, Chang Tsang-Jung, Lee ChengShang, and Hsu Kathryn Hua, 2011, "Improvement of Statistical Typhoon Rainfall Forecasting with NEURAL NETWORK-Based Southwest Monsoon Enhancement", Terr. Atmos. Ocean. Sci, Vol. 22, No. 6, pp. 633-645.

[95] Joshi Jignesh, Patel Vinod M., 2011, "Rainfall-Runoff Modeling Using Artificial Neural Network (A Literature Review)", National Conference on Recent Trends in Engineering \& Technology.

[96] El-Shafie Amr H., Shafie A. El-, Mazoghi Hasan G. El, Shehata A. and Taha Mohd. R., 2011, "Artificial neural network technique for rainfall forecasting applied to Alexandria, Egypt",

[97] Mekanik F., Lee T.S. and Imteaz M. A., 2011, "Rainfall modeling using Artificial Neural Network for a mountainous region in West Iran".

[98] Kaur Amanpreet, Singh Harpreet, 2011, "Artificial Neural Networks in Forecasting Minimum Temperature", International Journal of Electronics \& Communication Technology, Vol. 2, Issue 3, pp. 101-105.

[99] El-Shafie A., Jaafer O. and Akrami Seyed Ahmad, 2011, "Adaptive neuro-fuzzy inference system based model for rainfall forecasting in Klang River, Malaysia", International Journal of the Physical Sciences, Vol. 6(12), pp. 28752888.

[100] Tripathy Asis Kumar, Mohapatra Suvendu, Beura Shradhananda, Pradhan Gunanidhi, 2011. "Weather Forecasting using NEURAL NETWORK and PSO", International Journal of Scientific \& Engineering Research, Volume 2, Issue 7, pp.1-5.

[101] El-Shafie A, Noureldin A., Taha M. R., and Hussain A., 2011, "Dynamic versus static neural network model for rainfall forecasting at Klang River Basin, Malaysia", Hydrol. Earth Syst. Sci., vol. 8, pp. 6489-6532.

[102] Geetha G.,. Selvaraj R Samuel, 2011, "Prediction of monthly rainfall in Chennai using back propagation neural network model", International Journal of Engineering Science and Technology, Vol. 3 No. 1, pp. 211-213.

[103] Reshma T., Reddy K. Venkata, Pratap Deva, 2011, "Determination of Distributed Rainfall- Runoff Model Parameters Using Artificial Neural Network", International Journal of Earth Sciences and Engineering, Volume 04, No 06 , pp. 222-224

[104] Raju M.Mohan,. Srivastava R. K, Bisht Dinesh C. S., Sharma H. C., and Kumar Anil, 2011, "Development of Artificial Neural-Network-BasedModels for the Simulation of Spring Discharge", Hindawi Publishing Corporation, Volume 2011, pp. 1-11.

[105] Kavitha M.Mayilvaganan,.Naidu K.B, 2011, "NEURAL NETWORK and Fuzzy Logic Models for the Prediction of groundwater level of a watershed",
International Journal on Computer Science and Engineering, Vol. 3 No. 6, pp. 2523-2530.

[106] El-shafie A., Mukhlisin M., Najah Ali A. and Taha M. R., 2011, "Performance of artificial neural network and regression techniques for rainfall-runoff prediction", International Journal of the Physical Sciences, Vol. 6(8), pp. 1997-2003.

[107] Afshin Sarah, Fahmi Hedayat, Alizadeh Amin, Sedghi Hussein and Kaveh Fereidoon, 2011, "Long term rainfall forecasting by integrated artificial neural network-fuzzy logic-wavelet model in Karoon basin", Scientific Research and Essays, Vol. 6(6), pp. 1200-1208.

[108] Siou1 Line Kong A, JohNeural Networket Neural Networke, Borrell Valérie, Pistre Séverin, 2011, "Complexity selection of a neural network model for karst flood forecasting: The case of the Lez Basin (southern France)", Journal of Hydrology, vol. 403, pp. 367-380.

[109] Saima H., Jaafar J., Belhaouari S., Jillani T.A., 2011, "Intelligent Methods for Weather Forecasting: A Review", IEEE,

[110] Sawaitul Sanjay D., Prof. Wagh K. P., Dr. Chatur P. N., 2012, "Classification and Prediction of Future Weather by using Back Propagation Algorithm-An Approach", International Journal of Emerging Technology and Advanced Engineering, Volume 2, Issue 1, pp. 110-113.

[111] S Karmakar, M K Kowar, P Guhathakurta, Evolving and Evaluation of 3LP FFBP Deterministic NEURAL NETWORK Model for District Level Long Range Monsoon Rainfall Prediction, J. Environmental Science \& Engineering, , National Environmental Engineering Research Institute, Nagpur, INDIA, ISSN 0367-827, Vo 51, No. 2, pp. 137-144, April 2009. URL: http://www.neeri.res.in/jese.html.

[112] S Karmakar, M K Kowar, $\mathrm{P}$ Guhathakurta, Development of an 8-Parameter Probabilistic Artificial Neural Network Model for Long-Range Monsoon Rainfall Pattern Recognition over the Smaller Scale Geographical Region -District, IEEE Computer Society, IEEE Xplore 2.0,, DC, USA, ISBN 978-0-7695-3267-7, pp. 569-574, July 2008

http://www2.computer.org/portal/web/csdl/doi/10.1109/IC ETET.2008.225.

http://portal.acm.org/citation.cfm?id=1445475

[113] S. Karmakar, M K Kowar, P Guhathakurta, Development of Artificial Neural Network Models for Long-Range Meteorological Parameters Pattern Recognition over the Smaller Scale Geographical RegionDistrict, IEEE Xplore 2.0, IEEE Computer Society, Washington, DC, USA, ISBN 978-1-4244-2806-9, pp. 1-6, Dec. 2008

URL:http://ieeexplore.ieee.org/xpl/freeabs_all.jsp?isnumbe $r=4798312 \&$ arnumber $=4798370 \&$ count $=184 \&$ inde $x=54$.

[114] S Karmakar, M K Kowar, P Guhathakurta, LongRange Monsoon Rainfall Pattern Recognition \& Prediction for the Subdivision 'EPMB' Chhattisgarh Using Deterministic \& Probabilistic Neural Network, IEEE Xplore 2.0, IEEE Computer Society, Washington, DC, USA, ISBN 978-0-7695-3520-3, pp. 376-370, Feb. 2009 http://www2.computer.org/portal/web/csdl/doi/10.1109/IC APR.2009.24. 
[115] Peter et al.,(1979), Collinearity and Stability in the Estimation of Rainfall-Runoff model parameters, Journal of Hydrogy,42,91-108.

[116] Kitanidis.P.K., \& Bras.R.L.,(1980),Adaptive Filtering through detection of isolated transient error in rainfallrunoff models, Water resources research ,16,740-748

[117] Martinec.J. (1982), Runoff Modeling from Snow Covered Area, IEEE Trans, 20(3), 259-262.

[118] Baumgartner,M.F., Seidel, K. and Martinec.J. (1987). Toward Snowmelt Runoff Forecast Based on Multisensor Remote-Sensing Information, IEEE Trans., 25(6), 746750 .

[119] Vandewiele.G.L., and Yu.C. (1992), Methodology and comparative study of monthly water balance models in Belgium, China and Burma, Journal of Hydrology, 134(14), 315-347.

[120] Kumar,V.S.,Paul,P.R.,Ramaana Rao, CH.L.V.,Haefner.H., and Seibel.K.,(1993), JAHS Publecation, 218, 315-347.

[121] Kember,G., and Flower,A.C. (1993), Forecasting river flow using nonlinear dynamics, Stochastic Hydrology and Hydraulics, 7, 205-212.

[122] Seidel, K., Brusch,W., and Steinmeier,C.(1994), Experiences from Real Time Runoff Forecasts by Snow Cover Remote Sensing, IEEE Trans., 2090-2093.

[123] Shi, J., and Dozier,J. (1995), Inferring Snow Wetness Using C-Band Data from SIR-C's Polarimetric Synthetic Aperture Radar, IEEE Trans., 33(4),905-914.

[124] Franchinia,M., Helmlinger,T.K.R.,FoufoulaGeorgioub.E., and Todini,E. (1996), Stochastic storm transposition coupled with rainfall-runoff modeling for estimation of exceedance probabilities of design floods, Journal of Hydrology, 175,511-532.

[125] Xia,J., O'Connor,K.M., Kachroo,R.K., and Liang,G.C. (1997), A non-linear perturbation model considering catchment wetness and its application in fiver flow forecasting, Journal of Hydrology, 200, 164-178.

[126] Franchini,M., and Galeati,G., (1997), Comparing several genetic algorithm schemes for the calibration of conceptual rainfall-runoffmodels, Bydrological SciencesJournal-des Sciences Hydrologiques, 42(3), 357-379.

[127] Bach,H., Lampart,G., Strasser.G., and Mauser,W., (1999), First Results of an Integrated Flood Forecast System Based on Remote Sensing Data, IEEE Trans., 6(99), 864-866

[128] Sivakumar, B., Phoon, K.K., and Liong S.Y., (1999), A systematic approach to noise reduction in chaotic hydrological time series, Journal of Hydrology, 219(34), 103-135.

[129] Sajikumar, N., and Thandavewara, B.S., (1999), A non-linear rainfall-runoff modelusing an artificial neural network, Journal of Hydrology, 216(1-2), 32-55.

[130] Dibike.Y.B., and Solomatine.D.P. (1999), River Flow Forecasting Using Artificial Neural Networks, Elsevier, 26(1), 1-7.

[131] Gmez-Landesa,E., and Rango,A. (2000), Snow
Mapping Technilque at Subpixel Level for Small Basins, IEEE Trans, 3,1140-1142.

[132] Schaper.J., and Seidel.K.,(2000) ,Modelling daily runoff from snow and glacier melt using remote sensing data,EARSeL-SIG-Workshop Land Ice and Snow, Dresden/FRG, June 16 - 17, 308-317

[133] Toth,E., Brath,A., and Montanari,A., (2000), Comparison of short-term rainfall prediction models for real-time flood forecasting, Journal of Hydrology, 239, 132-147.

[134] Mallor,D., Sheffield,J., O'Connel,P.E., and Metcalfe,A.V., (2000), A stochastic space-time rainfall forecasting II: Application of SHETRAN and ARNO rainfall runoff models to the Brue catchment, Hydrology \& Earth System Sciences , 4(4), 617-626.

[135] Sivapragasam,C., Liong,S.Y., $\quad$ and Pasha,M.F.K.,(2001), Rainfall and runoff forecasting with SSA-SVM approach, Journal of Hydroinformatics, 141152.

[136] Chang,F.J., Liang,J.M, and Chen,Y.C.,(2001), Flood Forecasting Using Radial Basis Function Neural Networks, IEEE Trans, 31(4), 530-535.

[137] G'omez-Landesa,E., and Rango,A.,(2002), Operational snowmelt runoff forecasting in the Spanish Pyrenees using the snowmelt runoff model, HYDROLOGICAL PROCESSES, 16, 1583-1591.

[138] Randall,W.A., and Tagliarini,G.A.,(2002), Using Feed Forward Neural Networks to Model the Effect of Precipitation on the Water Levels of the Northeast Cape Fear River, IEEE Trans, 338-342.

[139] CNeural Networkas,B.,FNeural Networki,A.,Pintusb,M., and Sechib,G.M.,(2002), Neural network models to forecast hydrological risk, IEEE Trans, 623-626.

[140] Karna,J.P., Pulliainen,J., Huttunen,M., and Koskinen,J.,(2002), Assimilation of SAR data to operational hydrological runoff and snow melt forecasting model, IEEE Trans, 1146-1148.

[141] Brath,A.,Montanari,A., and Toth,E.,(2002), Neural networks and non-parametric methods for improving realtime flood forecasting through conceptual hydrological models, Hydrology and Earth System Sciences, 6(4), 627640

[142] Mahabir,C.,Hicks,F.E., and Fayek,A.R.,(2003), Application of fuzzy logic to forecast seasonal runoff, Hydrological Process, 17, 3749-3762.

[143] Slomatine,D.P., and Dulal.K.N.,(2003), Model trees as an alternative to neural networks in rainfall-runoff modelling, Hydrological Sciences-Journal-des Sciences Hydrologiques, 48(3), 399-411.

[144] Gaume,E., and Gosset,R.,(2003), Overparameterisation, a major obstacle to the use of artificial neural networks in hydrology, Hydrol. Earth Syst. Sci., 7, 693-706.

[145] Hossain,F., Anagnostou,E.N., and Dinku.T.,(2004), Sensitivity Analyses of Satellite Rainfall Retrieval and Sampling Error on Flood Prediction Uncertainty, IEEE 
Trans, 42(1), 130-139.

[146] Tigkas,D., and Tsakiris,G.,(2004), Medbasin: Mediterranean rainfall-runoff software package, EW Publication, 5(6), 3-11.

[147] Murphy.C., Dr. Charlton.R., Dr. Sweeney.J., Dr.Fealy.R.,(2004),Catering for uncertainity in a conceptual Rainfall-Runoff model: Model preparation for climate change impact assessment and the application of GLUE using Latin Hypercube sampling, National Hydrology Seminar 64-74.

[148] Corani,G., and Guariso,G.,(2005), Coupling Fuzzy Modeling and Neural Networks for River Flood Prediction, IEEE Trans, 35(3), 382-390.

[149] Khan,M.S., and Coulibaly,P.,(2005), Streamflow Forecasting with Uncertainty Estimate Using Bayesian Learning for NEURAL NETWORK, IEEE Trans, 26802685.

[150] Valença,M., Ludermir,T., and Valença,A.,(2005), Modeling of the rainfall-runoff relationship with artificial neural network, IEEE Trans.

[151] Knebl,M.R., Yang,Z.L., Hutchison,K., and Maidment,D.R.,(2005), Regional scale flood modeling using NEXRAD rainfall, GIS, and HEC-HMS/RAS: a case study for the San Antonio River Basin Summer 2002 storm event, Journal of Environmental Management, 75, 325-336.

[152] Nayak,P.C.,Sudheer,K.P., and Ramasastri,K.S.,(2005), Fuzzy computing based rainfall-runoff model for real time flood forecasting, , Hydrological Process, 19, 955-968.

[153] Chang,N.B., and Guo,D.H.,(2006), Urban Flash Flood Monitoring, Mapping, and Forecasting via a Tailored Sensor Network System, IEEE Trans, 757-761.

[154] Ghedira,H., Arevalo,J.C., Lakhankar,T., Azar.A., Khanbilvardi,R., and Romanov.P.,(2006), The Effect of Vegetation Cover on Snow Cover Mapping from Passive Microwave Data, IEEE Trans, 148-153.

[155] Liu,C.H., Chen,C.S., Su.H.C., $\quad$ and Chung.Y.D.,(2006), Forecasting Models for the Ten-day Streamflow of Kao-Ping River, IEEE Trans, 1527-1534.

[156] Li,Q., Chen,S., and Wang,D.,(2006), An Intelligent Runoff Forecasting Method Based on Fuzzy sets, Neural network and Genetic Algorithm, IEEE Trans.

[157] Huan,W.U., Xiuwan,C., and Xianfeng,Z.,(2006), A Cellular Automata Based Distributed Model for Simulating Runoff in LeAnhe Watershed, IEEE Trans, 1032-1035.

[158] Du,J., Xie,S., Xu,Y., Xie.H., Hu,Y., and Wang,P.,(2006), Flood Simulation with Distributed Hydrological Approach Using DEMs and Remotely Sensed Data, IEEE Trans, 1048-1051.

[159] Tayfur,G., Vijay and Singh,V.P., and Asce.F.,(2006), NEURAL NETWORK and Fuzzy Logic Models for Simulating Event-Based Rainfall-Runoff, Journal of Hydraulic Engineering,1321-1330.

[160] Cheng,C.T., Chau,C.W., and Li,X.Y.,(2007), Hydrologic Uncertainty for Bayesian Probabilistic Forecasting Model Based on BP NEURAL NETWORK, IEEE Trans.
[161] Jiang,G., Shen,B., and Li.Y.,(2007), On the Application of Improved Back Propagation NeuralNetwork in Real-Time Forecast. IEEE Trans.

[162] Ju,Q., Hao,Z., Zhu,C., and Liu,D.,(2007), Hydrologic Simulations with Artificial Neural Networks, IEEE Trans.

[163] Broersen,P.M.T.,(2007), Error Correction of RainfallRunoff Models With the ARMAsel Program, IEEE Trans, 56(6), 2212-2219.

[164] Ji,L., and Bende,W.,(2007), Parameters Selection for SVR based on the SCEM-UA Algorithmand Its Application on Monthly Runoff Prediction, IEEE Trans, 48-51.

[165] Moore,R.J.,(2007), The PDM rainfall-runoff model, Hydrology and Earth System Sciences, 11(1), 483-499.

[166] Lohani,A.K., Goel,N.K., and Bhatia,K.K.,(2007), Deriving stage-discharge-sediment concentration relationships using fuzzy logic, Hydrological Sciences Journal, 52(4), 793-807.

[167] Jenicek,M., (2007), Rainfall-runoff modelling in small and middle-large catchments- an overview, Hydrological Sciences Journal, 305-313.

[168] Jingbo,L., Zengchuan,D., Dezhi,W., and Shaohua.L.,(2008), Research on Runoff Forecast Model Based on Phase Space Reconstruction, IEEE Trans, 53395343 .

[169] Lake,I.,(2008)., Operational forecasts of algae blooms in the Baltic Sea, IEEE Trans.

[170] Li,C., and Yuan,X.,(2008), Research and Application of Data Mining for Runoff Forecasting, IEEE Trans, 795798.

[171] Liu,C.H., Chen,C.S., and Huang,C.H.,(2008), Revising One Time Lag Of Water Level Forecasting With Neural Fuzzy System, IEEE Trans, 617-621.

[172] Pei,W., and Zhu.Y.Y.,(2008), A Multi-Factor Classified Runoff Forecast Model Based on Rough Fuzzy Inference Method, IEEE Trans,221-225.

[173] Xu,Q., Ren,L., Yu,Z., Yang,B., and Wang,G.,(2008) Rainfall-runoff modeling at daily scale with artificial neural networks, IEEE Trans, 504-508

[174] Sang,Y., and Wang,D.,(2008), A Stochastic Model for Mid-to-Long-Term Runoff Forecast, IEEE Trans, 44-48.

[175] Liu,F., and Jiang,D.,(2008), Nonlinear Forecast Modeling Based on Wavelet Analysis,IEEE Trans, 622625 .

[176] Sun,X.L.,Tan,Y.M.,and Xu.X.C.,(2008), BP Neural Network Model Based on Reconstruction Phase Space and Its Application in Runoff Forecasting, IEEE Trans, 794797.

[177] Liu.F., Pan.H., and Jiang,D.,(2008), An Improved Markov Chain Monte Carlo Scheme for Parameter Estimation Analysis, IEEE Trans, 702-706.

[178] Wiriyarattanakul,S., Auephanwiriyakul,S., and Umpon.N.T.,(2008), Runoff Forecasting UsingFuzzy Support Vector Regression, IEEE Trans.

[179] Guo,H., Dong,G.Z., and Chen,X.,(2008), WNEURAL 
NETWORK Model for Monthly Runoff Forecast, IEEE Trans, 1087-1089.

[180] Remesan,R., Shamim,M.A.,Han,D. and Mathew,J.,(2008), ANFIS and NNARX based RainfallRunoff Modeling, IEEE Trans, 1454-1459.

[181] Archer,D.R., and Fowler,H.J.,(2008), Using meteorological data to forecast seasonal runoff on the River Jhelum, Pakistan, Journal of Hydrology, 361, 10-23.

[182] Aytek,A., Asce,M., and Alp,M.,(2008), An application of artificial intelligence for rainfall-runoff modeling, J. Earth Syst. Sci., 117(2), 145-155.

[183] Solaimani,K.,(2009), Rainfall-runoff Prediction Based on Artificial Neural Network (A Case Study: Jarahi Watershed), American-Eurasian J. Agric. \& Environ. Sci, 5(6). 856-865.

[184] Zhang,L.P., Song,X., Sheng,T., and Peng,T.,(2009), The Neural Networkual runoff forecasting research based on the theory of cointegration and error correction model, IEEE Trans, 1-4.

[185] Ren,Z., and Hao,Z.C.,(2009), Application of Moving Windows Autoregressive Quadratic Model in Runoff Forecast, IEEE Trans, 200-203.

[186] Wang,H.F., Chen,W.Y., and Song,S.I.,(2009), Design of Jinan City Flood Prevention and Warning DecisionMaking Support System based on SQL Server and GIS, IEEE Trans, 488-492.

[187] Ping,H.,(2009), Wavelet neural network based on BP algorithm and its application in flood forecasting, IEEE Trans.

[188] Zhu,Y.Y., and Pei.W.,(2009), Research of a Boundary Prolongation Method in RunoffForecast Based on Wavelet Transform,IEEE Trans, 1254-1258.

[189] Min,F., and Wu,X.,(2009), Local Semi-Linear Regression for River Runoff Forecasting, IEEE Trans, 556561 .

[190] Lu,Y., and Chen,X.,(2009), A Rapidly and Accurately Calculating Method of The Three Gorges Reservoir Dynamic Storage, IEEE Trans.

[191] Yan,J., Liu.Y.,Wang,J., Cao,H., and Zhao,H.,(2009), BP model applied to forecast the water and sediment fluxes in the Yellow River Mouth, IEEE Trans.

[192] Yan,J., Liu.Y.,Wang,J., Cao,H., and Zhao,H.,(2009), RBF model applied to forecast the water and sediment fluxes in Lijin section, IEEE Trans.

[193] Luna.I., Soares.S.,Lopes.J.E.G., $\quad$ and Ballini.R.,(2009),Verifying the use of evolving fuzzy systems for multi-step ahead daily inflow forecasting, IEEE Trans.

[194] Sihui.D.,(2009), A Forecast Model of Hydrologic Single Element Medium and Long-period Based on Rough Set Theory,IEEE Trans,19-25.

[195] Guo.J, Xiong.W., and Chen.H.,(2009),Application of Rough Set Theory to Multi-factor Medium and Longperiod Runoff Prediction in Danjing Kou Reservoir,IEEE Trans, 177-182.
[196] Acar.R., Senocak.S., and Sengul.S.,(2009),Snow Hydrology Studies in the Mountainous Eastern Part of Turkey,IEEE Trans,1578-1582.

[197] Xu.J., Zha.J., Zhang.W., Hu.Z., and Zheng.Z.,(2009),Mid-Short-Term daily Runoff forecasting by NEURAL NETWORKs and multiple process-based Hydrological models IEEE Trans,526-529.

[198] Xui.J., Zhu.X., Zhang.W., Xui.X., and Xian.J.,(2009),Daily streamflow forecasting by Artificial Neural Network in a large-scale basin,IEEE Trans,487-490.

[199] Feng.L.H., and Zhang.J.Z.,(2009), Application of NEURAL NETWORK in Forecast of Surface Runoff, IEEE Trans.

[200] Hundecha.Y., Bardossy.A., and Werner.H.,(2009),Development of a fuzzy logic-based rainfall-runoff model, Hydrological Sciences Journal,46(3),363-376.

[201] Bulygina.N., McIntyre.N., and Wheater.H.,(2009),Conditioning rainfall-runoff model parameters for ungauged catchments and land management impacts analysis, Hydrol. Earth Syst. Sci.,13,893-904.

[202] Hung.N.Q., Babel.M.S., Weesakul.S., and Tripathi.N.K.,(2009),An artificial neural network model for rainfall forecasting in Bangkok,Thailand, Hydrol. Earth Syst. Sci,13,1413-1425.

[203] Dadhwala,V.K., Aggarwal,S.P., $\quad$ and Mishra,N.,(2010),Hydrological Simulation of Mahanadi River Basin and Impact of Land Use / Land Cover Change on Surface Runoff Using a Macro Scale Hydrological Model, ISPRS TC VII Symposium XXXVIII,165-169.

[204] Kafle.T.P., Hazarika.M.K., Karki.S., Shrestha.R.M., Sharma.R., and Samarkoon.L.,(2010), Basin scale RainfallRunoff modelling for flood forecasts, IEEE Trans.

[205] Changying.L.,and Huagui.H.,(2010),Application Research on Hydrological Forecasting Based on Grey Prediction Model,IEEE Trans,290-293.

[206] Longxi.H., and Hong.J.,(2010),Impact of Sand Excavation in the Pearl River System on Hydrology and Environment,IEEE Trans.

[207] Xu.J., Wei.J., and Liu.Y.,(2010),Modeling Daily Runoff in a Large-scale Basin based on Support Vector Machines,IEEE(International Conference on Computer and Communication Technologies in Agriculture Engineering), 601-604

[208] Deshmukh.R.P., and Ghatol.A.,(2010),Comparative study of Jorden and Elman model of neural network for short term flood forecasting, IEEE Trans.,400-404.

[209] Li.X., Zhao.K., and Zheng.X.,(2010),An Error Analysis Method for Snow Depth Inversion Using Snow Emission Model,IEEE Trans.

[210] Wang.W., and Qiu.L.,(2010),Prediction of Neural Networkual Runoff Using Adaptive Network Based Fuzzy Inference System,IEEE Trans.

[211] Wang.W., Xu.D., and Qiu.L.,(2010),Support Vector Machine with Chaotic Genetic Algorithms for Neural Networkual Runoff Forecasting,IEEE Trans.,(671-675). 
[212] Ding.Z., Zhang.J., and XIE.G.,(2010),LS-SVM Forecast Model of Precipitation and Runoff Based on EMD,IEEE Trans.,1721-1725.

[213] Liu.Y., Chen.Y., Hu.J., Huang.Q., and Wang.Y.,(2010),Long-term Prediction for Autumn Flood Season in Danjiangkou Reservoir Basin Based on OSR-BP Neural Network, IEEE Trans., 1717-1720.

[214] Yan.J., Chen.S., and Jiang.C.,(2010),The Application of BP and RBF Model in the Forecasting of the Runoff and the Sediment Transport Volume in Linjin Section,IEEE Trans.,1892-1896.

[215] Liu.J., Dong.X., and Li.Y.,(2010),Automatic calibration of hydrological model by shuffled complex evolution metropolis algorithm,IEEE Trans.,256-259.

[216] Huang.M., and Tian.Y.,(2010),Design and implementation of a visual modeling tool to support interactive runoff forecasting,IEEE Trans.,270-274.

[217] Jizhong.B., Biao.S., Minquan.F., Jianming.Y., and Likun.Z.,(2010),Adaptive regulation ant colony system algorithm - radial basis function neural network model and its application IEEE Trans.

[218] Huang.M., and Tian.Y.,(2010),SVM-Based Visual Modeling System for Enhancing the flexibility of Interactive Runoff Forecasting,IEEE .

[219] Pradhan.R., Mohan P., Pradhan.M.P., Ghose.M.K., Agarwal.V.S., and Agarwal.S.,(2010) Estimation of RainfallRunoff using Remote Sensing and GIS in and around Singtam, East Sikkim, International Journal of Geomatics and Geosciences,1(3), 466-476.

[220] Shengtang.Z., Xiaojia.G., Yun.J.,(2011),Stormwater Utilization as an Enviromentalfriendly method to Alleviate Urban water resources Crisis:Taking Qingdao as an Example, IEEE Trans.,17221725 .

[221] Fu.Y.C., and Wei.C.J.,(2011),Method Study of Water Quality Control in Polluted Hun-Tai River Basin,IEEE Trans.

[222] Linke.H., Karimanzira.D., Rauschenbach.T., and Pfutzenreuter.T.,(2011),Flash flood prediction for small rivers,IEEE Trans.,86-91.

[223] Wang.X.,(2011),Application of Computer Simulation in the Reservoir Flood Control,IEEE Trans.

[224] Ma.X., Ping.J., Yang.L., Yan.M., and Mu.H.,(2011),Combined Model of Chaos Theory, Wavelet and Support Vector Machine for Forecasting Runoff Series and its Application, IEEE Trans.,842-845.

[225] Huaqil.W., Maosheng.Z., and Peicheng.,L.,(2011),Long-term Trend Analysis for the Runoff Series in Yulin,IEEE Trans.,1062-1065.

[226] Hu.C.H.., Wu.Z.N., Wang.J.J.,and Liu.L.,(2011),Application of the Support Vector Machine on Precipitation-Runoff Modelling in Fenhe River,IEEE Trans.,1099-1103.

[227] Ilker.A., Kose.M., Ergin.G., and Terzi.O.,(2011)An Artificial Neural Networks Approach to Monthly Flow Estimation,IEEE Trans.,325-328.
[228] Huang.G., and Wang.L.,(2011),Hybrid Neural Network Models for Hydrologic Time Series Forecasting Based on Genetic Algorithm,IEEE Trans.,1347-1350.

[229] Du.D., and Zhu.Z.Y.,(2011),The Neural Networkual Runoff Simulation Based on Pan-Kriging Method of Time Domain,IEEE Trans.,5469-5471.

[230] Zhen-min.Z., Xuechao.W., and Ke.Z.,(2011),RainfallRunoff Forcast Method Base on GIS, IEEE Trans.,24062409.

[231] Zhang.R., and Wang.Y.,(2011),Research on daily runoff forecasting model of lake IEEE Trans., 1648-1650.

[232] Yan.Q., Wei.J., Lin.L., Yang.Y., Zhu.X., and Shao.J.,(2011),Predicting Soil Erosion in Sloping Hilly Areas of Central Sichuan Based on SVM Model,IEEE Trans.,313-317.

[233] Yanxun.S., Jianhua.W.,and Peiyue.L.,(2011),Application of System Theory in the Calculation of Groundwater Resources Availability in Balasu Water Source,IEEE Trans.,707-710.

[234] Weilin.L.,Lina.L., and Zengchuan.D.,(2011),Neural network model for hydrological forecasting based on multivariate phase space reconstruction,IEEE Trans.,663667.

[235] Aiyun.L., and Jiahai.L.,(2011),Forecasting Monthly Runoff Using Wavelet Neural Network Model,IEEE Trans.,2177-2180.

[236] Zhang.N.,and Lai.S.,(2011),Water Quantity Prediction Based on Particle Swarm Optimization and Evolutionary Algorithm Using Recurrent Neural Networks,IEEE Trans.,2172-2176.

[237] Chen.Z., Li.L., and Bakir.M.,(2011),Application of improved TOPMODEL in rainstorm region IEEE Trans.,2901-2906.

[238] Chen.Z., and Li.L.,(2011),Advanced HBV Model Research Based on GIS Applying in Partial Rainstorm Area,IEEE Trans.,5733-5737.

[239] Liang.J., Yang.Q., Liao.R., Han.C., Jing.G., and He.X.,(2011),Web-based System for Rainfall-runoff Forecast in Beijing Metropolis,IEEE Trans.,6201-6204

[240] Limlahapun.P., Fukui.H., Yan.W., and Ichinose.T.,(2011),Integration of flood forecasting model with the web-based system for improving flood monitoring, and the alert system,IEEE Trans., 767-772.

[241] Wu.C.L., and Chau.K.W.,(2011),Rainfall-Runoff Modelling Using Artificial Neural Network Coupled with Singular Spectrum Analysis, Journal of Hydrology,399(34),394-409.

[242] Wanga.E., Zhenga.H., Chiewa.F., Shaob.Q., Luo.J., and Wang.Q.J.,(2011),Monthly and seasonal streamflow forecasts using rainfall-runoff modeling and POAMA predictions,IEEE Trans., 3441-3447.

[243] Patil. S.,Patil.S., and Valunjkar.S.,(2012),Study of Different Rainfall-Runoff Forecasting Algorithms for Better Water Consumption, International Conference on Computational Techniques and Artificial Intelligence,327330. 
[244] Brocca.L., Moramarco.T., Melone.F., and Wagner.W.,(2012),Assimilation of Surface- and Root-Zone ASCAT Soil Moisture Products Into Rainfall-Runoff Modeling,IEEE Trans., 50(7),2542-2555.

[245] Shengtang.Z., Peng.C., and Miaomiao.L.,(2012),Discussion on Soil and Water Conservation Activities Hydrological Effects Simulation in the Loess Plateau,IEEE Trans.,241-244.

[246] Shah.H., Jaafar.J., Ibrahim.R., Saima.H., and Maymunah.H.,(2012),A Hybrid System Using Possibilistic Fuzzy C-Mean and Interval Type-2 Fuzzy Logic for Forecasting: A Review IEEE Trans.,532-537.

[247] Xiao-lin.G.,Li-zi.Z., Jun.S. and Ning-ning.F.,(2012),A Multi-scenario Model for Mid-long Term Hydro-Thermal Optimal Scheduling,IEEE Trans.

[248] Bell.B., Wallace.B., and Zhang.D.,(2012),Forecasting River Runoff through Support Vector Machines,IEEE Trans.,58-64.

[249] Li.K., Ji.C., Zhang.Y., Xie.W., and Zhang.X.,(2012),Study of mid and long-term runoff forecast based on back-propagation neural network,IEEE Trans.,188-191.

[250] Zhang.N., Yao.L., and Wang.Q.,(2012),Study on OneDimensional Movement Model of Maliu Gully Debris Flow.

[251] Mittal.P., Chowdhury.S., Roy.S., Bhatia.N., and Srivastav.R.,(2012),Dual Artificial Neural Network for Rainfall-Runoff Forecasting,Journal of Water Resource and Protection, 4,1024-1028

[252] Jingwen.X., Wanchang.Z., Ziyan.Z., Jing.C., and Meiyan.J.,(2012),Establishment of a Hybrid RainfallRunoff Model for Use in the Noah LSM, Chinese Meteorological Society and Springer,26,85-92.

[253] Chen.S.M., Wang.Y.M., and Tsou.I.,(2013),Using artificial neural network approach for modelling rainfallrunoff due to typhoon, J. Earth Syst. Sci.,122(2),399-405.

[254] Gebregiorgis.A.S., and Hossain.F.,(2013),Understanding the Dependence of Satellite Rainfall Uncertainty on Topography and Climate for Hydrologic Model Simulation, IEEE Trans., 51(1),704718 .

[255] Phuphong.S., and Surussavadee.C.,(2013),An Artificial Neural Network Based Runoff Forecasting Model in the Absence of Precipitation Data: A Case Study of Khlong U-Tapao River Basin, Songkhla Province,Thailand,IEEE Trans.,73-77.

[256] Zhang.Y., Hong.Y., Wang.X.G., Gourley.J.J., Gao.J.D., Vergara.H.J. and Yong.B.,(2013) Assimilation of Passive Microwave Streamflow Signals for Improving Flood Forecasting: A First Study in Cubango River Basin, Africa,IEEE Trans.,1-16.

[257] Patil.S., and Walunjkar.,(2013),Rainfall-Runoff Forecasting Techniques For Avoiding Global Warming.Robertson.

[258] Robertson.D.E.,Pokhrel.P., $\&$ Wang.Q.J.,(2013),Improving statistical forecasts of seasonal streamflows using hydrological model
output,Hydrology and Earth System Sciences, 17,579-593

[259] Vleeschouwer.N.D., and Pauwels.V.R.N.,(2013),Assessment of the indirect calibration of a rainfall-runoff model for ungauged catchments in Flanders,Hydrology and Earth System Sciences, 17,2001-2016.

[260] Ramana.R.V., Krishna.B., Kumar.S.R., and Pandey.N.G.,(2013),Monthly Rainfall Prediction Using Wavelet Neural Network Analysis,Springer(Water Resour Manage),27,3697-3711.

[261] Karmakar.S.,Shrivastava.G., and Kowar.M.K.,(2014), Impact of Learning Rate and Momentum Factor in the Performance of Back-Propagation Neural Network to Identify Internal Dynamics of Chaotic Motion,Kuwait J.Sci,41(2),151-174.

[262] Journel, A. G., Huijbregts, C. J. ,1978: Mining geostatistics. Academic Press, New York

[263] Hornik, K., Stinchcombe, M., White, H., 1989: Multilayer feedforward networks are universal approximators. Neural Networks, 2, 359-366.

[264] Goovaerts, P., 1997: Geostatistics for natural resources evaluation, Oxford University Press, New York,

[265] Demyanov, V., 1998: Neural Network Residual Kriging Application for Climatic Data”, J. Geographic Information and Decision Analysis, 2 (2), 215-232.

[266] Huang, Y., Wong, P. M. Gedeon, T. D., 1998 Prediction of reservoir permeability using genetic algorithms, AI Applications, 12(1-3), pp. 67-75.

[267] Huang, Y., Wong, P.M., Gedeon, T.D., 1998: Spatial Interpolation Using Fuzzy Reasoning and Genetic Algorithms, J. Geographic Information and Decision Analysis, 2(2), $204-214$

[268] Ricardo, M. T., Palutikof, J.P., 1999: Simulation of Daily Temperatures for Climate Change Scenarios over Portugal: A Neural Network Model Approach, Climate research (Clim., Res.), 13, 45-59

[269] Guhathakurta, P., 1998: A Hybrid Neural Network Model for Long Range Prediction of All India Summer Monsoon Rainfall, Proc. WMO international workshop on dynamical extended range forecasting, Toulouse, France, November 17-21, 1997, PWPR No. 11, WMO/TD. 881, 157-161.

[270] Guhathakurta, P., 1999: Long Range Forecasting Indian Summer Monsoon Rainfall By Principle Component Neural Network Model, J. Meteor. \& Atomos. Phys., 71, 255-266.

[271] Guhathakurta, P., 1999: A Short Term Prediction Model for Surface Ozone At Pune: Neural Network Approach, Vayu mandal, 29(1-4), 355-358.

[272] Guhathakurta, P., 1999 : A Neural Network Model for Short Term Prediction of Surface Ozone at Pune, Mausam, 50(1), 91-98.

[273] Guhathakurta, P., Rajeevan, M., Thapliyal, V., 1999 Long Range Forecasting Indian Summer Monsoon Rainfall by Hybrid Principal Component Neural Network Model, Meteorology and Atmospheric Physics, Springer-Verlag, Austria. 
[274] Guhathakurta, P., 2000: New Models for Long Range Forecasts of Summer Monsoon Rainfall over North West and Peninsular India, Meteorology and Atmospheric Physics, 73 (3), 211-255.

[275] Rajeevan, M., Guhathakurta, P., Thapliyal, V., 2000, "New Models for Long Range Forecasting of a Monsoon Rainfall over Northwest and Peninsular India". Meteorology and Atmospheric Physics, 73, 211-225.

[276] Karmakar, S., Kowar, M. K., Guhathakurta, P., 2009: Evolving and Evaluation of 3LP FFBP Deterministic NEURAL NETWORK Model for District Level Long Range Monsoon Rainfall Prediction", J. Environmental Science \& Engineering, 51(2), 137-144

[277] Karmakar, S., Kowar, M. K., Guhathakurta, P., 2008: Development of Artificial Neural Network Models for Long-Range Meteorological Parameters Pattern Recognition over the Smaller Scale Geographical RegionDistrict", IEEE Xplore, IEEE Computer Society. Washington, DC, USA.

[278] Karmakar, S., Kowar, M. K., Guhathakurta, P., 2008: Development of an 8-Parameter Probabilistic Artificial Neural Network Model for Long-Range Monsoon Rainfall Pattern Recognition over the Smaller Scale Geographical Region -District, IEEE Xplore, IEEE Computer Society, Washington, DC, USA.

[279] Karmakar, S., Kowar, M. K., Guhathakurta, P., Development of a 6 Parameter Artificial Neural Network Model for Long-Range July Rainfall Pattern Recognition over the Smaller Scale Geographical Region District, CSVTU Research Journal, pp. 36-40.

[280] Karmakar, S., Kowar, M. K., Guhathakurta, P., 2009: Long-Range Monsoon Rainfall Pattern Recognition \& Prediction for the Subdivision 'EPMB' Chhattisgarh Using Deterministic \& Probabilistic Neural Network", IEEE Xplore, IEEE Computer Society, Washington, DC, USA.

[281] Karmakar, S., Kowar M. K., Guhathakurta P., 2009, Spatial Interpolation of Rainfall Variables using Artificial Neural Network", ACM DL, 547-552

[282] Snell, S. E., 2000, Spatial Interpolation of Surface Air Temperatures Using Artificial Neural Networks: Evaluating Their Use for Downscaling GCMs, Journal of Climate, 13, 886-895

[283] Antonić, O., Križan, J., Marki, A., Bukovec, D., 2001: Spatio-temporal interpolation of climatic variables over large region of complex terrain using neural networks, Ecological Modelling, 138, 255-263

[284] Rigol, J.P., Jarvis, C.H., Stuart, N., 2001: Artificial neural networks as a tool for spatial interpolation, International Journal of Geographical Information Science,

\section{$15,323-343$}

[285] Koike, K., Matsuda, S., Gu, B., 2001: Evaluation of Interpolation Accuracy of Neural Kriging with Application to Temperature-Distribution Analysis. Mathematical Geology, 33(4), 421-448. Kumar, S., :Neural Network Computer Engineering Serie, The McGraw-Hill, New Delhi, 2007, 104-152

[286] Bryan, B.A., Adams, J.M., 2001: Quantitative and Qualitative Assessment of the Accuracy of Neurointerpolated Neural Networkual Mean Precipitation and Temperature Surfaces for China, Cartography, 30 (2), Perth, Australia.

[287] Bryan, B.A., Adams, J. M., 2002: Three-Dimensional Neurointerpolation of Neural Networkual Mean Precipitation and Temperature Surfaces for China, Geographical Analysis, 34 (2), 93-111

[288] Iseri, Y. G. C. Dandy., Maier, R., Kawamura, A., Jinno, K., 2002: Medium Term Forecasting of Rainfall Using Artificial Neural Networks, Part 1 background and methodology, Journal of Hydrology , 301 (1-4), 1834-1840

[289] Silva, A. P., :2003, Neural Networks Application to Spatial Interpolation of Climate Variables, Carried Out By, STSM on the Framework of COST 719 ZAMG

[290] Attorre, F., Alfo, M., Sanctis, M., Francesconi, F., Bruno, F., 2007: Comparison of interpolation methods for mapping climatic and bioclimatic variables at regional scale, Int. J. Climatol., Royal Meteorological Society, Published online in Wiley InterScience (www.interscience.wiley.com) DOI: 10.1002/joc.1495

[291] Chattopadhyay, S., Chattopadhyay, G., 2008: Identification of the best hidden layer size for threelayered neural net in predicting monsoon rainfall in India, J. Hydroinformatics, 10 (2), 181-188

[292] Hung, N. Q., Babel, M. S., Weesakul, S., Tripathi N. K., 2009: An artificial neural network model for rainfall forecasting in Bangkok, Thailand, Hydrology and Earth System Sciences, 13, 1413-1425

[293] Mendes, D., Marengo, J., 2010: South America downscaling: using spatial artificial neural network, Geophysical Research Abstracts, 12, EGU2010-9475

[294] Sivapragasam, C., Arun, V.M., Giridhar, D., 2010, A simple approach for improving spatial interpolation of Rainfall using NEURAL NETWORK, Meteoro Atmos Phys, Springer, 109, 1-7

[295] Ghazanfari, S., Alizadeh, A., Farid, A., BNeural Networkayan, M., 2011: Comparison the PERSINEURAL NETWORK model with interpolation methods to estimate daily precipitation (A case study: North-Khorasan, Iran), Geophysical Research Abstracts, 13, EGU2011-12743 